\title{
Measuring and Modeling Fault Density for Plume-Fault Encounter Probability Estimation
}

\author{
Preston D. Jordan ${ }^{1 *}$, Curtis M. Oldenburg ${ }^{1}$ and Jean-Philippe Nicot ${ }^{2}$ \\ ${ }^{1}$ Earth Sciences Division \\ Lawrence Berkeley National Laboratory \\ Berkeley, California 94720 \\ ${ }^{2}$ Bureau of Economic Geology \\ Jackson School of Geosciences \\ University of Texas \\ Austin, Texas 78713
}

\begin{abstract}
Emission of carbon dioxide from fossil-fueled power generation stations contributes to global climate change. Storage of this carbon dioxide within the pores of geologic strata (geologic carbon storage) is one approach to mitigating the climate change that would otherwise occur. The large storage volume needed for this mitigation requires injection into brine-filled pore space in reservoir strata overlain by cap rocks. One of the main concerns of storage in such rocks is leakage via faults. In the early stages of site selection, site-specific fault coverages are often not available. This necessitates a method for using available fault data to develop an estimate of the likelihood of injected carbon dioxide encountering and migrating up a fault, primarily due to buoyancy. Fault population statistics provide one of the main inputs to calculate the encounter probability. Previous fault population statistics work is shown to be applicable to areal fault density statistics. This result is applied to a case study in the southern portion of the San Joaquin Basin with the result that the probability of a carbon dioxide plume from a previously planned injection had a 3\% chance of encountering a fully seal offsetting fault.
\end{abstract}

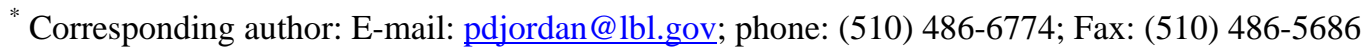




\section{Introduction}

Fossil-fuel fired electrical power plants emitted $41 \%$ of the carbon dioxide due to energy usage in the United States in 2008 (EIA, 2009). Storage of a portion of this carbon dioxide in the pore space of geologic strata (geologic carbon storage) is one possible mitigation for the portion of climate change otherwise attendant upon emitting this pollutant to the atmosphere.

Geologic carbon storage is envisioned in both strata from which oil and/or gas have been produced as well as strata containing primarily saline waters, termed saline aquifers. If geologic carbon storage is to be a significant mitigation, storage in saline aquifers is necessary because the volume of the depleted oil and gas fields is not sufficient relative to the quantity of carbon dioxide emitted from large, fixed sources. This is due to the burning of coal sourced from the near surface by most large, fixed sources as well as the relatively lower volumetric density of carbon in carbon dioxide as compared to fossil fuels.

Leakage of stored carbon dioxide out of designated subsurface storage volumes is one of the main concerns regarding geologic carbon storage. For example, carbon dioxide could migrate from a storage site into a hydrocarbon resource, such as a natural gas deposit. Fault zones are considered one of the main potential leakage pathways (Benson and Cook 2005). For such leakage to occur carbon dioxide must both encounter a fault and the fault must be relatively more transmissive than the surrounding rock. Certainty about the location and character of fault zones varies from higher in depleted oil and gas reservoirs to lower in saline aquifers. Consequently a more deterministic assessment of leakage risk due to faults is possible for storage in mature oil and gas reservoirs and a more probabilistic assessment is necessary for saline aquifers, particularly in the early site selection phase of a project. 
Two inputs are needed for assessing the probability of a carbon dioxide plume encountering a fault - the footprint of the plume and fault statistics (Jordan et al. 2011). The smaller the footprint and/or the smaller the fault density, the smaller the likelihood the plume will encounter a fault. Numerical modeling can provide realizations of the plume footprint. Available fault coverages can provide an understanding of the fault population.

This paper develops a more readily usable fault statistical approach applicable to geologic carbon storage, and applies that approach to develop fault statistics from publicly available coverages for input to a plume-fault encounter probability estimate for a proposed storage test site: the Western Regional Carbon Sequestration Partnership’s (WestCarb) Phase III injection site at Kimberlina northwest of Bakersfield, California. The injection horizon for this planned experiment is a saline aquifer for which there is little publicly available data regarding faulting. There are numerous oil and gas fields in the vicinity with publicly available structure maps, however. Statistics regarding fault orientation and fault population are developed from these coverages allowing calculation of the probability the planned Kimberlina carbon dioxide plume will encounter a fault.

\section{Background}

Numerous investigators have found that fault length and displacement populations can often be represented by a power-law distribution. This finding is based upon field research (e.g., Watterson et al. 1996), physical modeling (e.g., Ackerman et al. 2001), and numerical simulations (e.g., Cowie et al. 1995). Power-law distributions are of the form

$$
N \propto a S^{-C}
$$


where $N$ is the number of faults of a size greater than $S$, and $C$ is the power law exponent (notations from Watterson et al. 1996). For instance, $N$ can represent the number of faults greater than a certain length determined from a two-dimensional sample space, such as a geologic map. Alternately, $N$ can represent the number of faults with greater than a certain displacement, $d$, encountered in a one-dimensional sample space, such as a scan line. When $d$ (known as the displacement cutoff) is substituted for $S$, Equation 1 becomes

$$
N_{d} \propto d^{-C_{d}}
$$

where the subscript " $d$ " is for displacement cutoff.

Field studies, numerical simulations, and physical modeling have also indicated that at very low strains and high strains, fault density versus throw truncation is exponential rather than power law (Cowie at al. 1995 and Ackermann et al. 2001). They also show that $C_{d}$ declines with increasing strain during the initiation of faulting, and becomes constant with further strain. At initiation of strain, many small faults develop, and so $C_{d}$ is large. As strain continues, some of the faults grow and eventually link, while few new small faults develop, so $C_{d}$ decreases. Values reported in the literature are likely to emphasize lower values for $C_{d}$ as field studies are easier to carry out on more heavily faulted terrains. At very high strains, further development of one fault tends to dominate, and the fault population evolves toward a "characteristic" fault population, akin to a characteristic earthquake population.

\section{Fault Density Approach}

If $N$ represents the number of faults greater than a certain length, it is often difficult to measure in practice due to the confounding effects of fault intersections. Further, the orientation 
of the boundary of a fault coverage can introduce scatter in the fault density distribution measured from the coverage.

The areal density of faults, $F$, with a certain value of $d$ is easier to measure. It can be accurately calculated by measuring the length of faults with greater than a certain displacement occurring in a coverage area and dividing by that area. It avoids handling of fault intersections inherent in defining the number of faults based on length, and it does not suffer from bias introduced by the orientation of coverage margins. Use of $F$ is workable because it is proportional to $N_{d}$, as shown following, so can be substituted for $N_{d}$ in Equation 2.

$N_{d}$ can be multiplied by the average length of fault $\left(l_{d}\right)$ represented by each fault intersection with one of multiple scan lines across a coverage. This value is proportional to the average sample-line spacing. Multiplying $N_{d}$ by $l_{d}$ yields

$$
l_{d} N_{d}=L
$$

where $L$ is the total length of faults with $d$ greater than a particular value. Obviously, $L$ can be directly measured from a fault map rather than through scan lines. Multiplying Equation 2 by $l_{d}$ yields

$$
l_{d} N_{d} \propto d^{-C_{d}}
$$

Substituting Equation 3 into Equation 4, and dividing by the total area of the sample domain, $A$, gives

$$
\frac{L}{A} \propto d^{-C_{d}}
$$

The value $L / A$ is the fault density, $F$, so Equation 5 can be rewritten 


$$
F \propto d^{-C_{d}}
$$

An additional implication of Equation 6 is that $F$ follows the same pattern as $N_{d}$ as strain accumulates.

Taking the log of Equation 6 gives

$$
\log F \propto-C_{d} \log d
$$

Equation 7 indicates a log-log plot of $F$ against $d$ will be linear if the fault population follows a power-law distribution. A semi-log plot of $F$ against $d$ will be linear if the distribution is exponential (very early stage or late stage strain).

Equation 7 implies that $F$ approaches infinity as $d$ approaches 0 . In practice, most fault population researchers have found, or believe based upon theoretical considerations, that the relationship is accurate down to displacements equivalent to several grain diameters for clastic rocks (e.g., Ackerman et al. 2001). Even this implies $F$ becomes very large at the actual lower limit of $d$. This suggests a high probability that a given $\mathrm{CO}_{2}$ plume will encounter a fault of some size. Of course, most such faults will have such small displacements as to not be of serious concern in terms of leakage. Consequently, the concern for leakage should focus on faults of a certain size (large enough to have a high probability of leakage), rather than on all faults encountered as is often the case currently.

As defined above, $F$ is a measure of fault density in a two-dimensional space. As such, $F$ provides a biased estimate of the fault density in the three-dimensional rock volume (Pickering et al. 1995). Due to the buoyancy of $\mathrm{CO}_{2}$, and typically much greater length and width than thickness of most proposed storage reservoirs, carbon dioxide plumes will typically be more two- 
than three-dimensional. As a result, $F$ is the proper parameter for estimating the probability of a $\mathrm{CO}_{2}$ plume encountering a fault with a given displacement.

However, three-dimensional fault density can enter back into consideration several steps after a plume encounters a fault. After such an encounter, the first issue is the flow and transport properties of the fault. If these properties are such that leakage via the fault can occur, then the next relevant issue is the vertical extent of the portion of the fault with these properties. If the extent of this portion of the fault is sufficient to allow leakage all the way from the $\mathrm{CO}_{2}$ plume to a volume of concern (i.e., a receptor such as an underground source of drinking water (USDW)), then analysis should proceed to consideration of impacts. If the extent of the leakage-capable portion of the fault is insufficient to allow direct leakage to a receptor, but sufficient to allow leakage out of the storage formation, then consideration of leakage via more complex pathways

must occur. This network is defined in part by the three-dimensional fault density, along with the distribution of permeable geologic units in relation to the fault density. Such considerations are outside of the current study, but the probability of flow through conductive fault networks with power-law populations is developed in Zhang et al. (2010).

\section{Fault Encounter Probability}

The other input to calculating the probability of a plume encountering a fault of a particular size is half the plume dimension perpendicular to the fault, $k$. This requires ascertaining the fault orientation mode from the fault coverages, as well as estimating the expected plume shape. The plume shape can be estimated from numerical simulations of the proposed carbon dioxide injection. With the fault density and fault perpendicular plume dimension, the encounter probability is calculated according to the equation 


$$
\operatorname{Pr}(g)=2 k F
$$

The derivation of this equation is given in Jordan et al. (2011).

If there is more than one fault strike mode, then multiple distributions of $F$ will have to be defined based upon measurements from the fault coverage. Each mode will also require a different $k$ unless the plume is radially symmetric. Equation 8 can then be used to calculate a $\operatorname{Pr}(g)$ for each mode for each fault size of interest.

\section{Case Study: The Kimberlina Phase III Pilot Test}

WESTCARB's Kimberlina Phase III pilot test project is located in the southern San Joaquin Basin in California about 27 km (17 mi.) northwest of Bakersfield, as shown on Figure 1. The San Joaquin Basin extends about $350 \mathrm{~km}$ (220 mi.) from the Stockton Arch to its southern terminus at the northern Transverse Ranges and averages 80-110 kilometers (50-70 miles) wide. It is bounded on the east by the Sierra Nevada and on the west by the Coast Ranges (NETL 2009). During the Mesozoic, the area was a fore-arc basin during subduction of the Farallon plate. By middle Tertiary time, the basin had become relatively isolated as a result of the transpressional margin that followed the passage of the Mendocino triple junction. The depositional environment generally progressed from deep marine in the Mesozoic to alluvial at present with a number of intervening transgression-regression sequences (Graham and Williams 1985).

During the Kimberlina Phase III pilot test, $1 \mathrm{Mt}\left(10^{6} \mathrm{t}=10^{9} \mathrm{~kg} ; 1.1 * 10^{6} \mathrm{~T}=2.2^{*} 10^{9} \mathrm{lbs}\right)$ of $\mathrm{CO}_{2}$ was planned for injection into the Vedder sandstones over four years (NETL 2009). The Vedder consists of interbedded sandstones and shales deposited on the marine slope, shelf and delta comprising a ramp (Bloch 1986). At the site, the Vedder has a thickness up to $160 \mathrm{~m}$ (520 
$\mathrm{ft})$, and occurs at a depth of 2,300 m (7,500 ft) (Wagoner 2009). Thick continuous shale units provide good overlying seals at the site and surrounding areas (Wagoner 2009). Faults in the vicinity appear to be primarily growth faults (McPherson 1978).

\section{Fault Data}

Detailed information on faults at and in the vicinity of the Kimberlina site is not available. However, there are 27 oil and gas fields within $24 \mathrm{~km}$ (15 mi.) of the Kimberlina site where faults have been mapped extensively as shown on Figure 2. Structure maps from these fields provide a basis for predicting the likely pattern and occurrence of faults at the Kimberlina site. These maps are available in Volume 1 of "California Oil and Gas Fields" by the California Division of Oil, Gas and Geothermal Resources (DOGGR 1998, with the exception of the Rose Field for which no data were available). An example structure map is shown on Figure 3.

The contour interval of most of these maps is 15 or $30 \mathrm{~m}$ ( 50 or $100 \mathrm{ft}$ ). The minimum

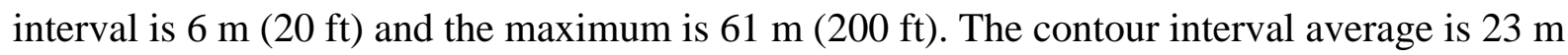

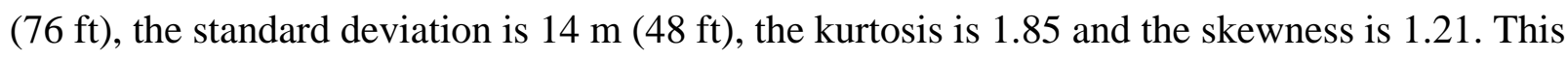
indicates the distribution of contour intervals is relatively symmetric and peaked.

The orientation and length of 956 fault segments were measured from the maps. Throws, as annotated on Figure 3, were generally linearly interpolated from the structure contours. Throws at fault intersections were measured from the interpolated elevation of the fault-block corners. Throws were measured at 1,046 points. The total fault length measured was $465 \mathrm{~km}$ (289 mi). The resulting data are presented in Appendix 1.

The structure maps indicate almost all the fault segments were normal. Fault-dip information was not given on the maps, so only the throw (vertical component of displacement) could be measured. McPherson (1978) indicates most of the faults are vertical, at least upsection 
from the Vedder, and likely subvertical at the Vedder. Therefore the throw is likely not much less than the dip component of displacement. As a result, measuring throw instead of dip displacement probably does not introduce significant errors.

Additionally, the offset perpendicular to bedding is likely more relevant to a fault's properties with respect to fluid flow than is the actual displacement as bedding perpendicular displacement is more related to the shale-gouge ratio. The shale-gouge ratio is the proportion of shale displaced past a particular point on a fault. Along fault permeability decreases with increasing shale gouge ratio, at least at lower values (Yielding et al. 1996). As the bedding dips in the vicinity of Kimberlina are generally small ( $7^{\circ}$ for the Vedder Formation), the offset perpendicular to the bedding is almost the same as the throw, further justifying the focus on throw.

\section{Fault Orientation}

The distribution of fault orientations is shown on Figure 4. The primary mode is north to northwest. A secondary mode is to the northeast to east-northeast. The distribution of fault orientations in oil and gas fields centered within $16 \mathrm{~km}$ (10 mi.) of the Kimberlina site is shown in Figure 5. The primary mode of fault orientation is to the north. One third of the fault length occurs in this $10^{\circ}$ interval. Three quarters of the fault length occurs in the north to northwest octant.

The distribution of fault orientations in oil and gas fields beyond $16 \mathrm{~km}$ (10 mi) but at least in part within $24 \mathrm{~km}$ (15 mi.) of the Kimberlina site is shown in Figure 6. The primary fault strike mode is to the northwest. About half of the fault length occurs in this mode. A fifth of the fault length occurs in a secondary northeast mode. A tenth of the fault length occurs in a tertiary north mode. 
Comparison of Figures 5 and 6 indicates that fault sets with distinctly different orientation occur near the Kimberlina site versus farther away. This suggests that faults in the vicinity of the Kimberlina site will strike north to north by northwest.

\section{Fault Data Aggregation}

The field structure maps are constructed on a wide variety of stratigraphic horizons. Figure 7 shows that the faults in the vicinity of Kimberlina tend to persist through the prePliocene Tertiary section, which includes the Vedder Formation (DOGGR 1998). The fault density for each field is defined as the field's total fault length divided by the area of each field's structure map.

The vertical distances from each mapped horizon to the Vedder Formation was measured from the geologic sections and/or stratigraphic columns available for each field (DOGGR 1998). Figure 8 shows the fault density from each structure map relative to the vertical distance from that horizon to the top of the Vedder. Relative map area is shown by symbol size.

The distribution of fault densities does not change appreciably within 1,500 meters (6,900 $\mathrm{ft}$ ) of the Vedder. Data beyond this are sparse, but suggest the density may be lower. Still, the figure supports aggregating the fault data from all the maps for the purpose of fault encounter probability estimation.

Figure 9 shows the approximate direction and distance from the Kimberlina site to each field, the size of each field and the fault density in each field. The figure shows there are almost no fields from the northwest to northeast of the Kimberlina site. Further, the fault density is higher from the northeast to southwest, and lower from the southwest to northwest, despite a slightly higher concentration of fields with maps based on smaller contour intervals in the latter. Unlike fault orientation, though, there is no obvious trend in fault density with distance. These 
data suggest that the Kimberlina site is in a transitional area between higher and lower fault densities.

Based upon Figure 9, the fault data from all the fields are aggregated for the purpose of calculating fault encounter probability in the Kimberlina area. Aggregation provides an average density that will account somewhat for the Kimberlina site's apparent position in an area of transitional fault density. As more fields exist in the quadrants with higher average density, it may be that the density aggregate from the fields overestimates the fault density in the vicinity of Kimberlina. This would lead to a higher than actual estimate of fault encounter probability.

\section{Fault Density Modeling}

Fault density is plotted against specific throw truncation in Figure 10. While it is tempting to see this distribution as exponential given the good fit to the data, low displacement faults are underreported due to the fault mapping resolution limit (Pickering et al. 1995). As a result, the actual fault population is larger than the measured data at the low end of the range. The exponential fit, as good as it is, actually under predicts the fault density at low throw cutoffs.

Alternatively, the throw truncation intervals and range of values fitted was varied to find the largest range that could be well fit linearly. This resulted in a line that lies above the data at low throw cutoff, in accord with the mapping resolution effect. The point of departure of the linear fit from the fault-density data is at a throw cutoff of approximately $20 \mathrm{~m}(65 \mathrm{ft})$. This is reasonable as it is slightly lower than the average contour interval of $23 \mathrm{~m} \mathrm{(76} \mathrm{ft)} \mathrm{for} \mathrm{the} \mathrm{oil} \mathrm{and}$ gas field structure maps. Consequently, the linear fit appears more likely to represent the actual fault population in the vicinity of the Kimberlina site, indicating that the fault population follows a power-law distribution. The power law fit also yields higher fault density estimates at low 
throw truncations, which makes it more conservative than the exponential fit for estimating leakage risk.

The linear fit also over predicts the fault density at high throw truncations relative to the data according Figure 10. This occurs due to the probability of undersampling of large faults in a given finite mapping area. This typically results in greater downscaling in the throw truncation range than in the fault density range. This causes the data to shift down at the highest throw truncations, the so-called "finite-range effect” of Pickering et al. (1995).

Pickering et al. (1995) presents a correction for this effect. The suggested correction was implemented by including the fault density at the two highest throw truncations in the data set for fitting, adding a constant to each fault density in the data set, and calculating a new linear fit. The constant was varied until the square of the correlation coefficient was maximized. A constant of $0.025 \mathrm{~km} / \mathrm{km}^{2}\left(0.04 \mathrm{mi} . / \mathrm{mi}^{2}{ }^{2}\right)$ provided the best fit. The corrected data and fit are shown on Figure 11. The $C_{d}$ resulting from this correction is 1.16 .

A comparison of $C_{d}$ values from Figures 10 and 11 provides additional support for taking the latter as more accurately representing the fault population than the former. The $C_{d}$ of 1.43 shown on Figure 10 is larger than values typically reported from field studies, which range from 0.5 to 1.0 (Yielding et al. 1996). Such a value would indicate that the fault network in the Kimberlina area is relatively undeveloped. As mentioned, the faults appear to be primarily due to growth faulting and so perhaps a lower total strain is reasonable. Conversely, most of the mapped faults intersect other faults, suggesting at least moderate development of the fault network. This would tend to support the contention that the $C_{d}$ on Figure 10 is too large. The corrected $C_{d}$ of 1.16 shown on Figure 11 is more commensurate with the reported range and the observed degree of fault network development. Further, as mentioned, lower 
values of $C_{d}$ correlate with a higher density of large offset faults relative to low offset faults. As large offset faults are of more concern for leakage (as discussed below), the lower estimate of $C_{d}$ is also more conservative with regard to estimating leakage risk.

\section{Throw Interpolation}

The throw at one end of a fault segment will typically be different from that at the other end. Some method for estimating the portion of the segment with $d$ must be chosen. This method could simply be a linear interpolation between the displacements at the two end points, or some higher order interpolation of displacement along the fault using multiple values. Alternatively, the segment length could simply be bifurcated with each half assigned the throw at nearest end. The simplicity of the latter strategy comes at the cost of error in $F$ for a particular $d$ given a specific fault, but this error should shrink to a generally small value for a larger fault set. In the case of the current set under consideration, fault densities at each value of $d$ were calculated using both the segment bifurcation and linear interpolation approaches. There was negligible difference in the distribution of $F$ resulting from these two methods, suggesting the simpler bifurcation method can be used without concern for larger fault sets.

\section{Fault Encounter Probability}

An estimate of the reservoir area swept by carbon dioxide due to the proposed injection can be measured from numerical simulation results. The anticipated $\mathrm{CO}_{2}$ plume at the Kimberlina site was numerically simulated using the ECO2N equation of state package of TOUGH2 (Pruess and Garcia 2002, Doughty 2010). The model simulated the injection of 250,000 $\mathrm{t} / \mathrm{yr}$ of $\mathrm{CO}_{2}$ for four years, then simulated migration and trapping of the plume over the next 46 years. Figure 12 shows $\mathrm{CO}_{2}$ saturation and saturation above residual saturation at several 
time steps in the numerical modeling. Saturation above residual is referred to as the mobile fraction. On Figure 12, zero is no saturation above residual, and one is $100 \%$ saturation.

The area within the outer contour on the last frame of Figure 12 is the region swept by CO2 since the start of injection. This area changes little after 30 years, and so is termed the "plume area" for the purposes of analyzing the probability of mobile $\mathrm{CO}_{2}$ encountering a fault. This definition of the plume area differs from other possible definitions, such as the area swept by dissolved $\mathrm{CO}_{2}$.

Considering the predominant fault orientation in the vicinity of the Kimberlina site as discussed above, the fault-perpendicular plume dimension measured from Figure 12 is $1.06 \mathrm{~km}$ (0.62 mi.), which is equal to $2 k$. Faults with throws that fully offset the caprock overlying a prospective storage reservoir are one particular focus of concern (not that leakage along faults with smaller throws is not possible). The sealing formations over the Vedder have a vertical thickness of approximately $180 \mathrm{~m}$ (600 ft). The corrected fault density equation on Figure 11 indicates the average density of faults with this throw truncation is $0.028 \mathrm{~km} / \mathrm{km}^{2}(0.046$ mi./mi. $\left.{ }^{2}\right)$. So the probability of the plume resulting from the proposed Kimberlina injection encountering such a fault is 3.2\% according to Equation 8.

\section{Conclusions}

Storage of carbon dioxide in subsurface reservoirs is one possible means for reducing greenhouse gas emissions. However, the volume of depleted oil and gas fields is insufficient and is likely to be further limited by concerns regarding injecting carbon dioxide into the remaining resource in place. Consequently, if this technological solution is to move forward storage in 
brine-filled reservoirs will need to occur. Less is known about these reservoirs than those containing oil and gas because there has been little economic incentive to characterize them.

The possibility of leakage is one of the main concerns regarding carbon dioxide storage, with leakage along faults a particular focus of concern. In order for leakage to occur, encounter of a fault needs to occur first, followed by movement along a fault. Statistics regarding areal fault density are one input to calculating the probability of such encounters. Past findings and formulations regarding fault population statistics can be applied as well to areal fault density. This provides a means to both check areal fault density statistics measured from available fault mapping, and to formulate these statistics for input. This is particularly useful when carrying out leakage risk assessment in the site-screening stage, or in the site evaluation stage, at sites with limited site-specific characterization of faults.

Once the probability of a plume encountering a fault of a particular size is known, some perspective on the probability of leakage along that fault can be gained from its throw and the lithology of the displaced section by calculating the shale-gouge ratio along the fault (Yielding et al. 1996). The probability of a fault plume encounter times the probability of fault leakage once an encounter has occurred comprises the total fault leakage probability. However, this presumes fault encounter and leakage along a fault are independent events. Consequently this approach would not hold in some cases, such as fields with a significant probability of induced seismicity on the faults of interest.

One outcome of the application of the fault-population approach to fault encounter probability assessment is the realization that $\mathrm{CO}_{2}$ plumes will encounter faults of some size in most geologic sequestration environments because small-offset faults occur at high densities. This does not mean a priori that significant leakage will necessarily occur via these smaller 
faults, as evidenced by the persistence of buoyant hydrocarbon deposits frequently, if not typically, occurring in association with faulted terrain. This understanding should shift the consideration of leakage via faults from a more simple concern for plumes encountering faults, to a more detailed assessment of which faults are likely to be of concern, and what happens if the plume encounters those faults.

\section{Acknowledgments}

We are grateful to Chris Doughty (LBNL) for sharing the Kimberlina Phase III pilot test simulation results, and to Jeff Wagoner (LLNL) for sharing his expertise regarding the geology of the southern San Joaquin Valley, particularly in the vicinity of the Kimberlina site. We thank Tiemi Onishi for providing an internal review. This said, the authors take full responsibility for the data analysis and conclusions presented. This work was supported in part by the $\mathrm{CO}_{2}$ Capture Project (CCP) of the Joint Industry Program (JIP), and by Lawrence Berkeley National Laboratory under U.S. Department of Energy Contract No. DE-AC02-05CH11231. 


\section{REFERENCES}

Ackerman, R. V., R. W. Schlische and M. O. Withjack (2001). The geometric and statistical evolution of normal fault systems: an experimental study of the effects of mechanical layer thickness on scaling laws. Journal of Structural Geology. 23, 1803-1819.

Bloch, R. B. (1986). Ramp-style deposition of Oligocene marine Vedder formation, San JoaquinValley. California, AAPG Bulletin. 70, 4.

Cowie, P. A., D. Sornette and C. Vanneste (1995). Multifractal scaling properties of a growing fault population. Geophysical Journal International. 122, 457-469.

Doughty, C. (2010). Investigation of $\mathrm{CO}_{2}$ plume behavior for a large-scale pilot test of geologic carbon storage in a saline formation. LBNL-2243E. Transport in Porous Media: Special Issue on Geologic Carbon Storage, published online, DOI 10.1007/s11242-009-9396-z, Springer.

Energy Information Agency (EIA) (2009). Emissions of greenhouse gases report. DOE/EIA0573(2008). Released 3 December 2009, revised 8 December 2009. http://www.eia.doe.gov/oiaf/1605/ggrpt/carbon.html.

Graham, S. A. and L. A. Williams (1985). Tectonic, depositional, and diagenetic history of Monterey Formation (Miocene), Central San Joaquin Basin, California. AAPG Bulletin. 69: 385-411.

Jordan, P.D., C.M. Oldenburg, and J.P. Nicot (2011). Calculating the probability of injected carbon dioxide plumes encountering faults. Submitted to the International Journal of Greenhouse Gas Control. 
McPherson, B. A. (1978). Sedimentation and trapping mechanisms in Upper Miocene Stevens and older turbidite fans of the southeastern San Joaquin Valley, California. AAPG Bulletin. 62, 2243-2274.

National Energy Technology Laboratory (NETL) (2009). West Coast Regional Sequestration Partnership - development phase. 4 p. http://www.netl.doe.gov/publications/factsheets/project/Proj596.pdf accessed on June 9, 2009.

Pickering, G., J. M. Bull and D.J. Anderson (1995). Sampling power-law distributions. Tectonophysics. 248, 1-20.

Wagoner, J. (2009). 3D Geologic Modeling of the Southern San Joaquin Basin for the Westcarb Kimberlina Demonstration Project- A Status Report. Lawrence Livermore National Laboratory, LLNL-TR-410813.

Watterson, J., J. J. Walsh, P. A. Gillispie and S. Eaton (1996). Scaling systematics of fault sizes on a large-scale range fault map. Journal of Structural Geology. 18, 199 - 214.

Yielding, G., B. Freeman, and D. T. Needham (1996). Quantitative fault seal prediction. AAPG Bulletin. 81, $897-917$.

Zhang, Y., C.M. Oldenburg, and S. Finsterle (2010). Percolation-theory and fuzzy rule-based probability estimation of fault leakage at geologic carbon sequestration sites. LBNL-2172E. Environmental Earth Sciences, 59 (7), 144-159; published online, DOI: 10.1007/s12665009-0131-4. 


\section{FIGURE CAPTIONS}

Figure 1. Location of the Kimberlina Phase III pilot test in the San Joaquin Basin in California (modified from Sheirer 2007).

Figure 2. Oil and gas fields in the vicinity of the Kimberlina site. The Kimberlina site is at the star. North is up. (modified from DOGGR 1998)

Figure 3. Structure map of Calders Corner oil field modified from DOGGR (1998). Italic values are interpolated throws in feet. Large values are interpolated elevations of fault-block corners in feet relative to sea level. Dashed line is boundary of coverage area. The Stevens is a productive zone in the Fruitvale, which is shown on Figure 7.

Figure 4. Percent of fault length occurring in $10^{\circ}$ strike intervals in oil and gas fields centered within 24 km (15 mi.) of the Kimberlina site.

Figure 5. Percent of fault length occurring in $10^{\circ}$ strike intervals in oil and gas fields centered within 16 km (10 mi.) of the Kimberlina site.

Figure 6. Percent of fault length occurring in $10^{\circ}$ strike intervals in oil and gas fields centered between $16 \mathrm{~km}$ (10 mi.) and $24 \mathrm{~km}$ (15 mi.) of the Kimberlina site.

Figure 7. Generalized section for the southeastern San Joaquin basin (DOGGR 1998).

Figure 8. Fault density for individual oil and gas fields plotted against the vertical distance from the structural map horizon to the Vedder Formation. Positive values indicate the Vedder is deeper than the section. Symbol area is proportional to field structure map area.

Figure 9. Approximate direction and distance to each field. Relative field size and fault density represented by circle diameter. Empty circles are fields without faults. 
Figure 10. Fault density versus throw truncation aggregated from the structure maps for the oil and gas fields shown on Figure 2. Data are shown as closed boxes. Heavy line is linear fit to selected data (see text). Lighter line is exponential fit to all data. Dashed lines are extrapolated from the fit lines.

Figure 11. Fault density versus throw truncation aggregated from the structure maps for the oil and gas fields shown on Figure 2. Data are shown as open boxes. Lighter line is linear fit to selected data (see text). Corrected data are shown as closed boxes. Heavy line is linear fit to selected corrected data. Dashed lines are extrapolated from the fit lines.

Figure 12. Numerically simulated total $\mathrm{CO}_{2}$ saturation and saturation in excess of residual. Total saturation is shown by contours. Saturation in excess of residual is shown by tints. Note the tints for saturation in excess of residual are defined on a log scale. Coordinates are in meters. North is up. (Courtesy of Christine Doughty, LBNL). 


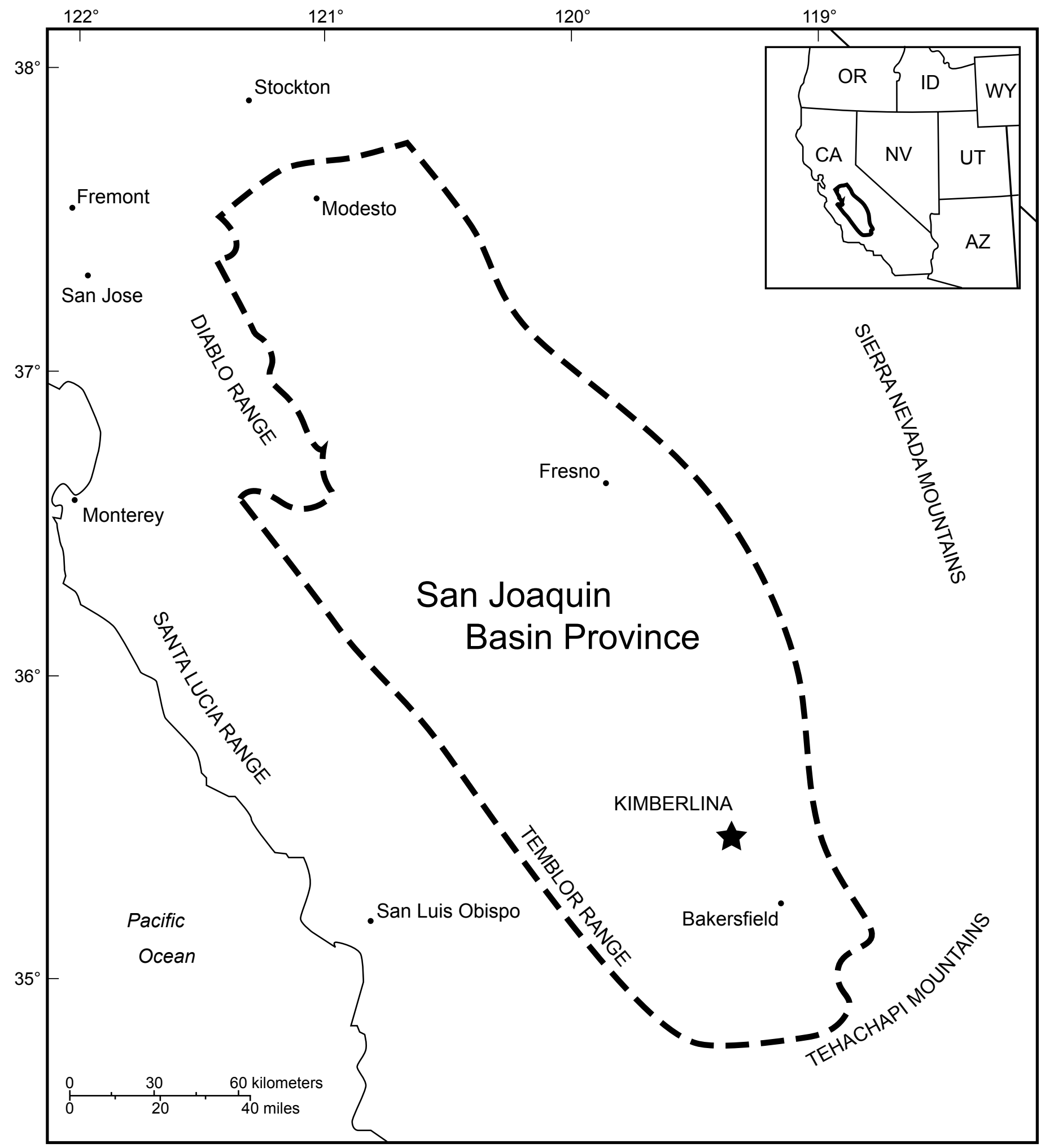

Figure 1 


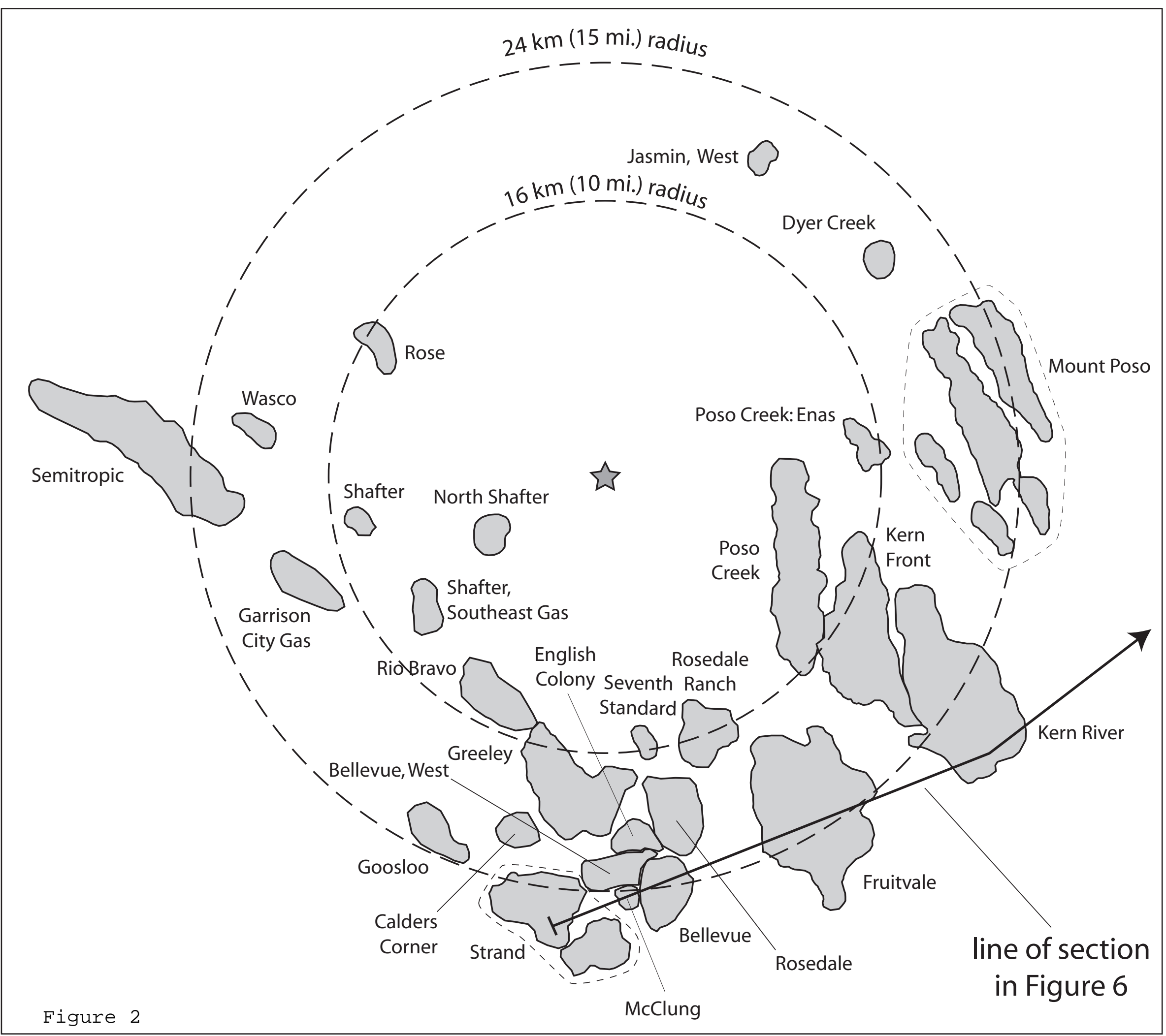




\section{T29S R25E}

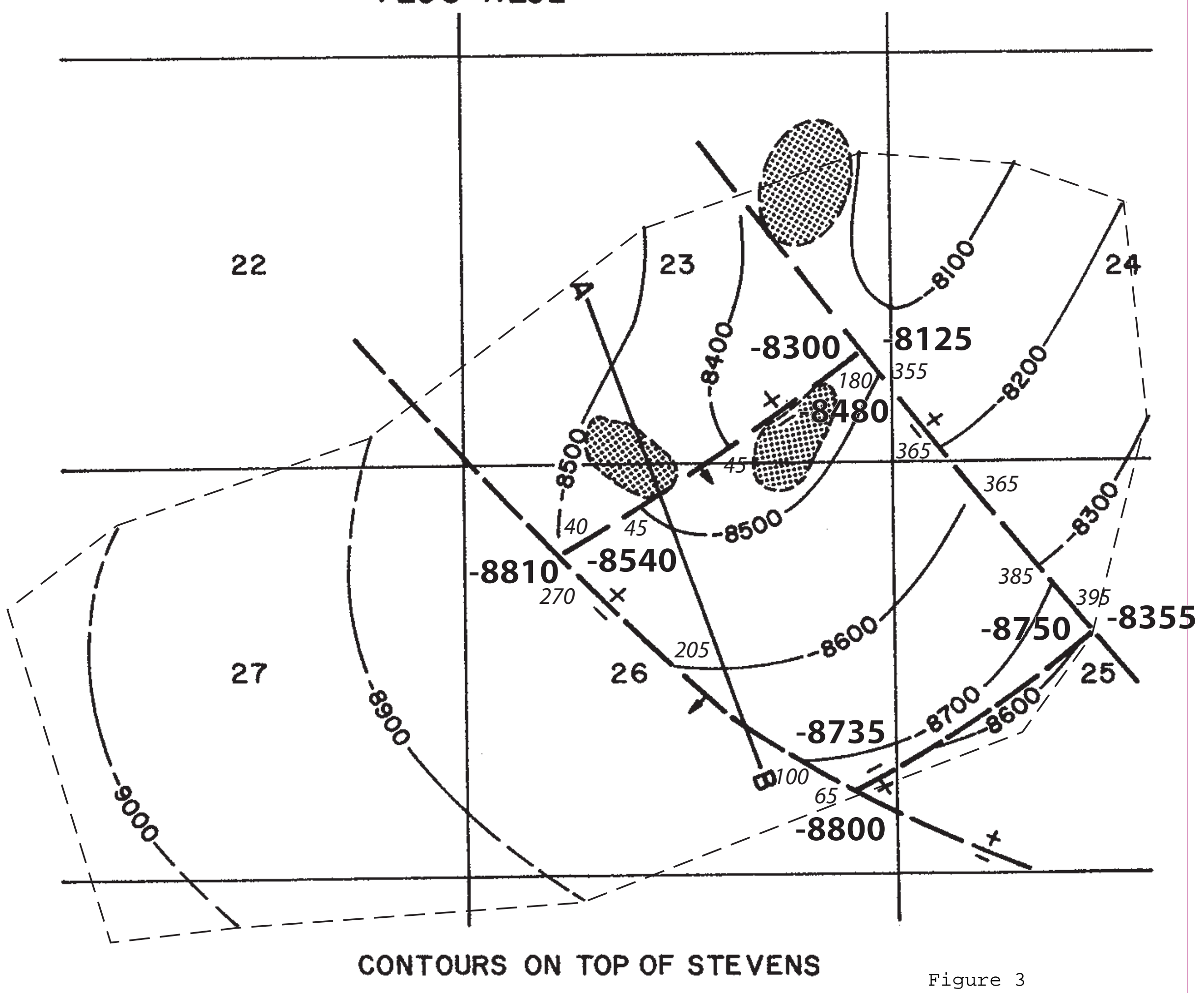




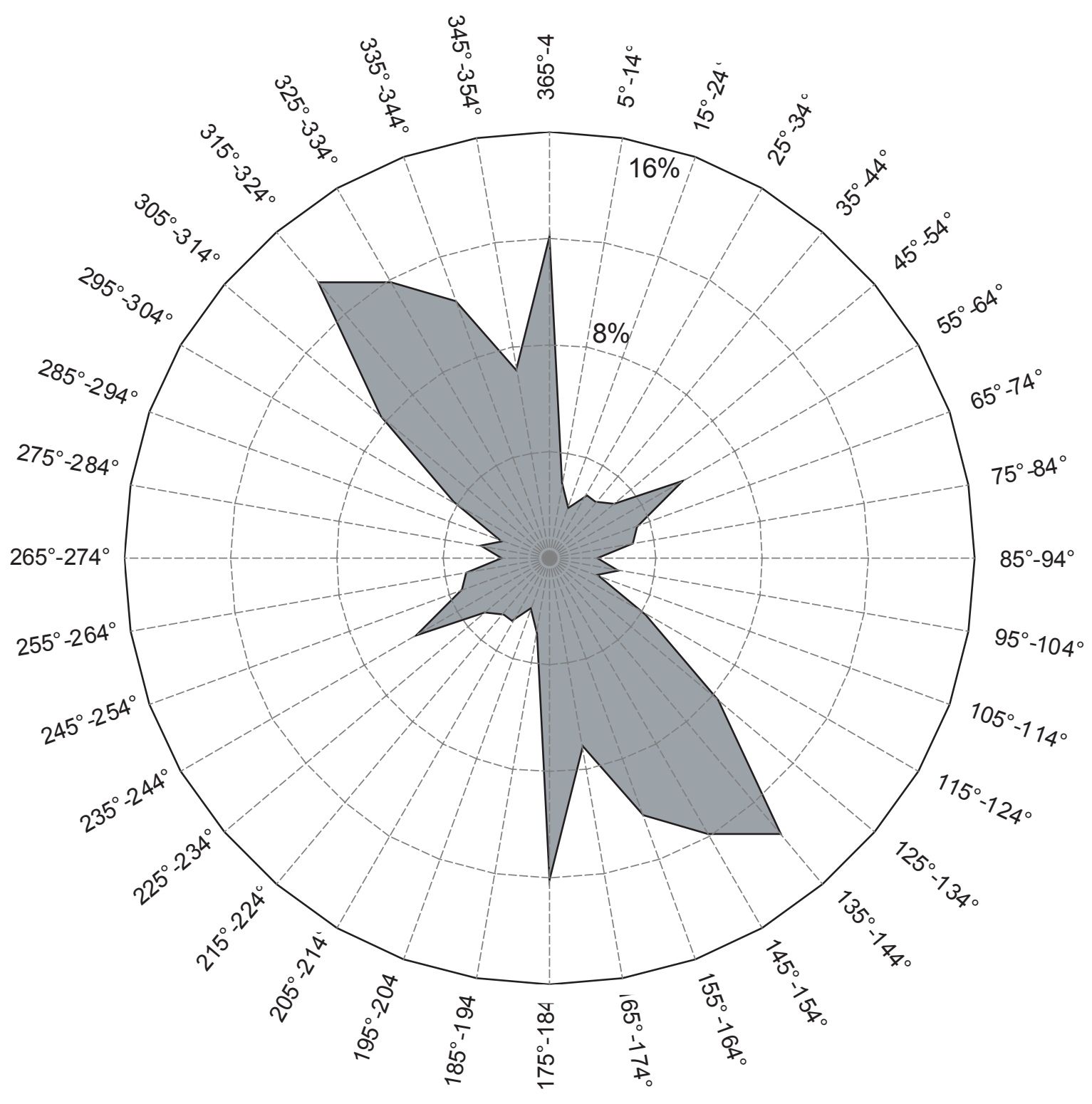

total fault length: $465 \mathrm{~km}$ (289 mi.) 


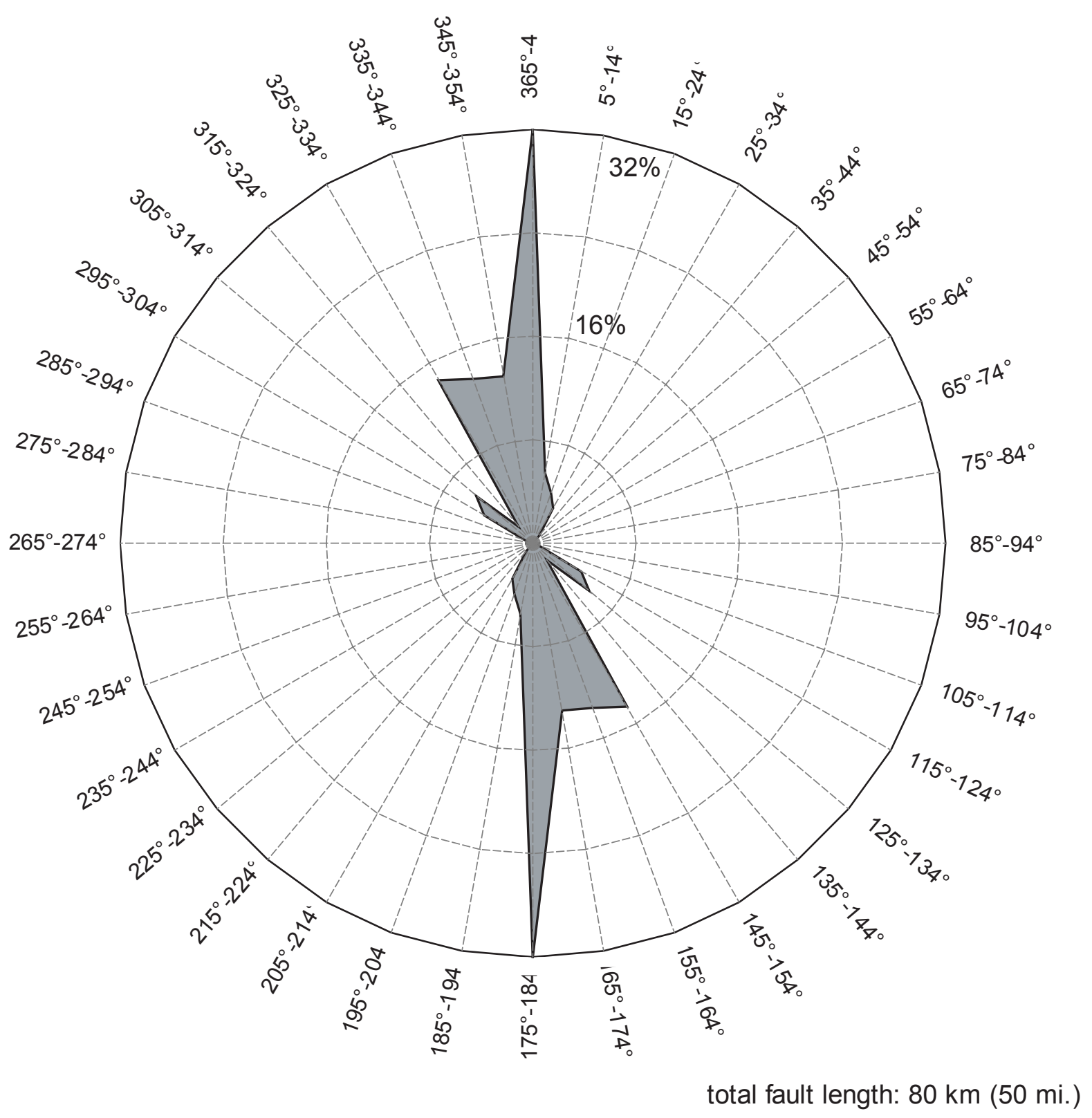

Figure 5 


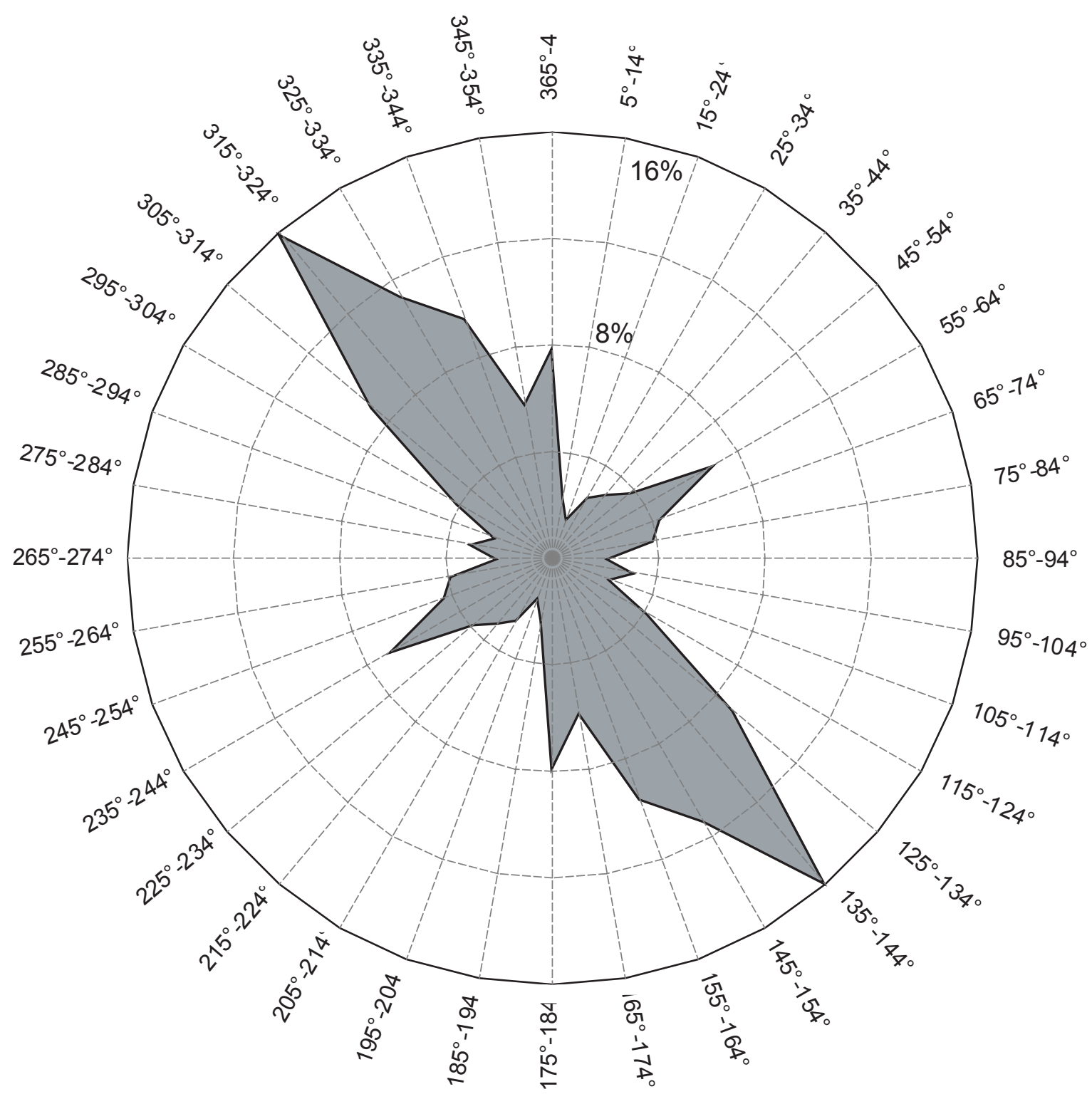

total fault length: $384 \mathrm{~km}$ (239 mi.) 


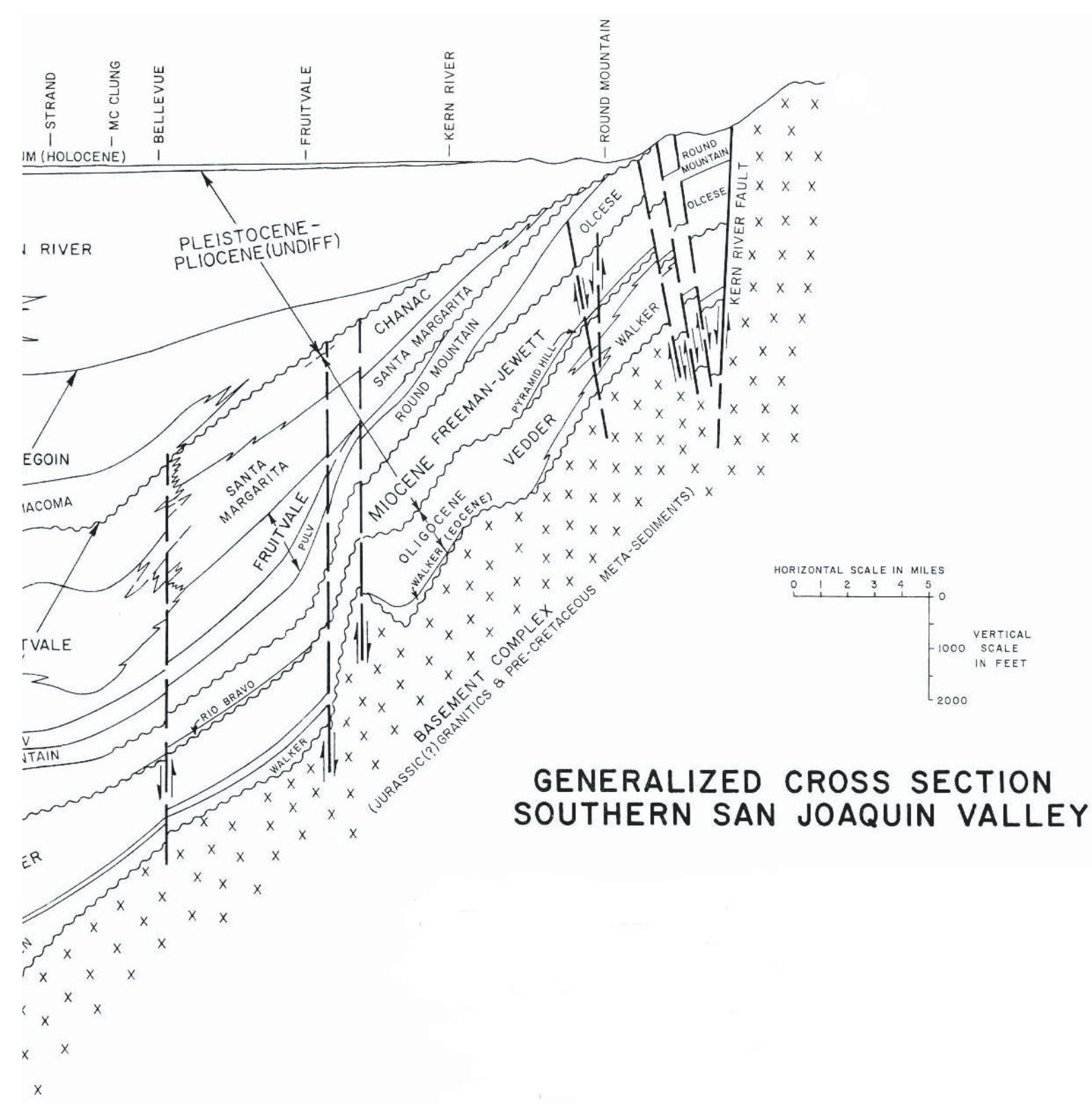




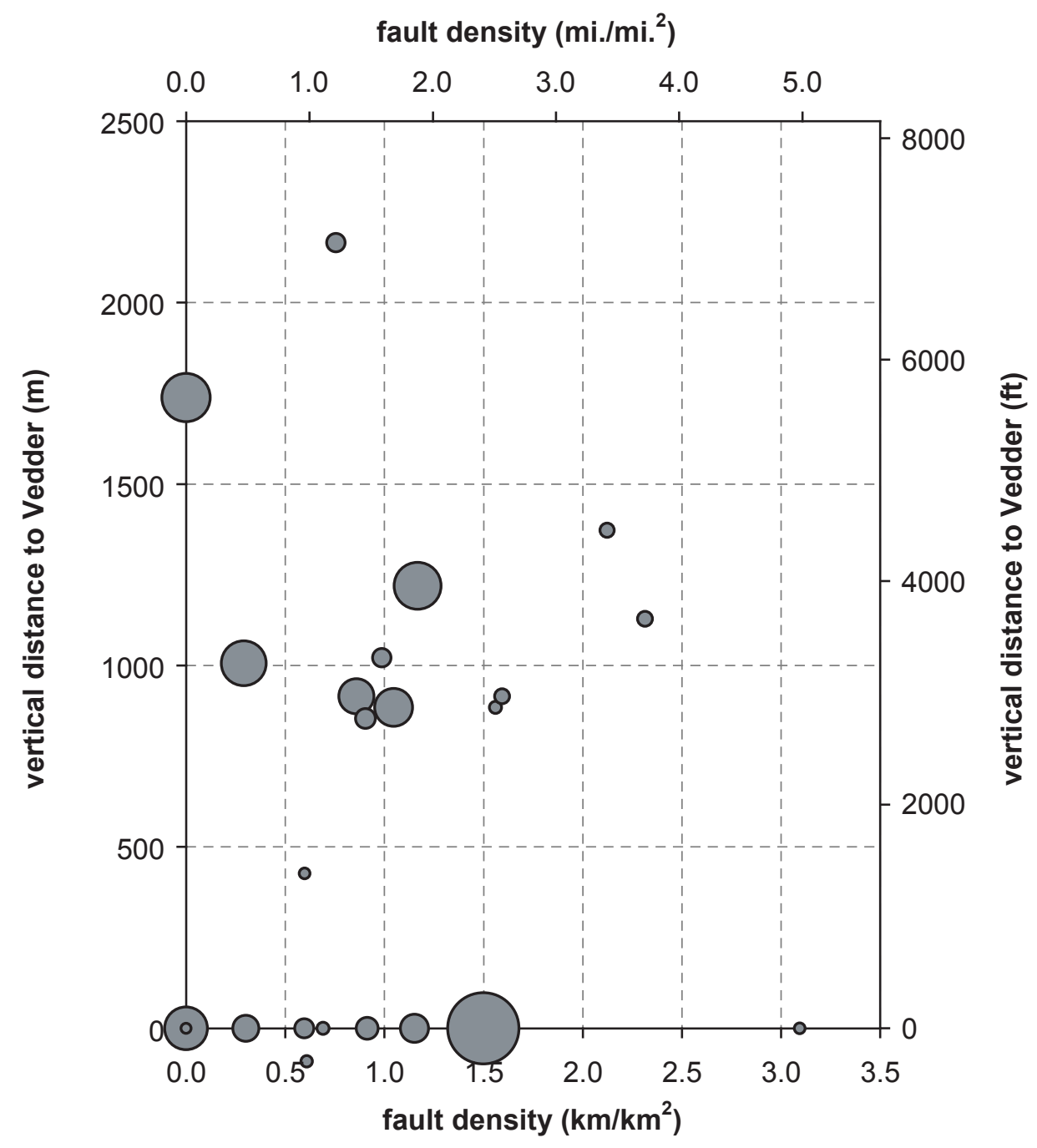

Figure 8 


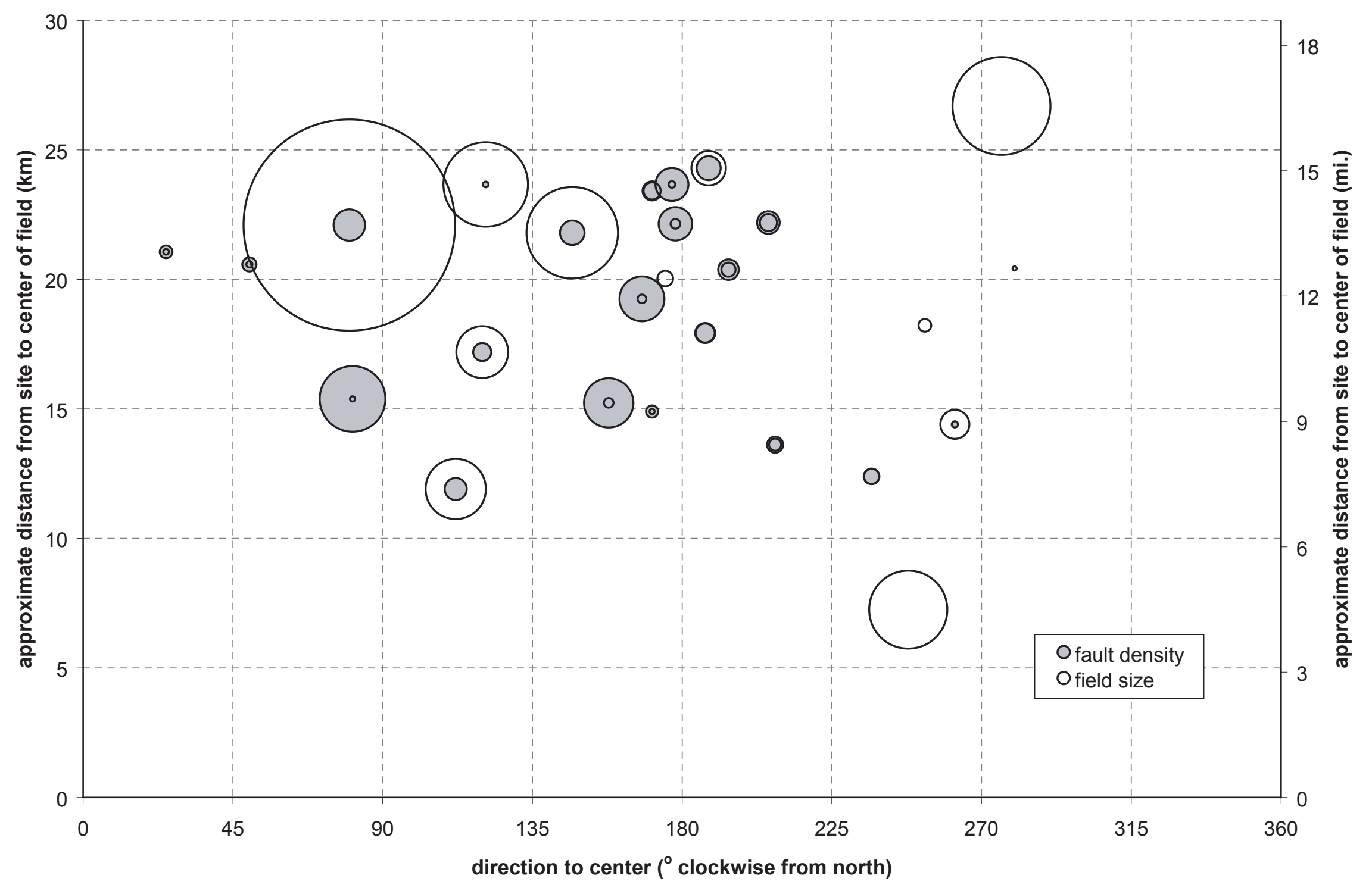

Figure 9 


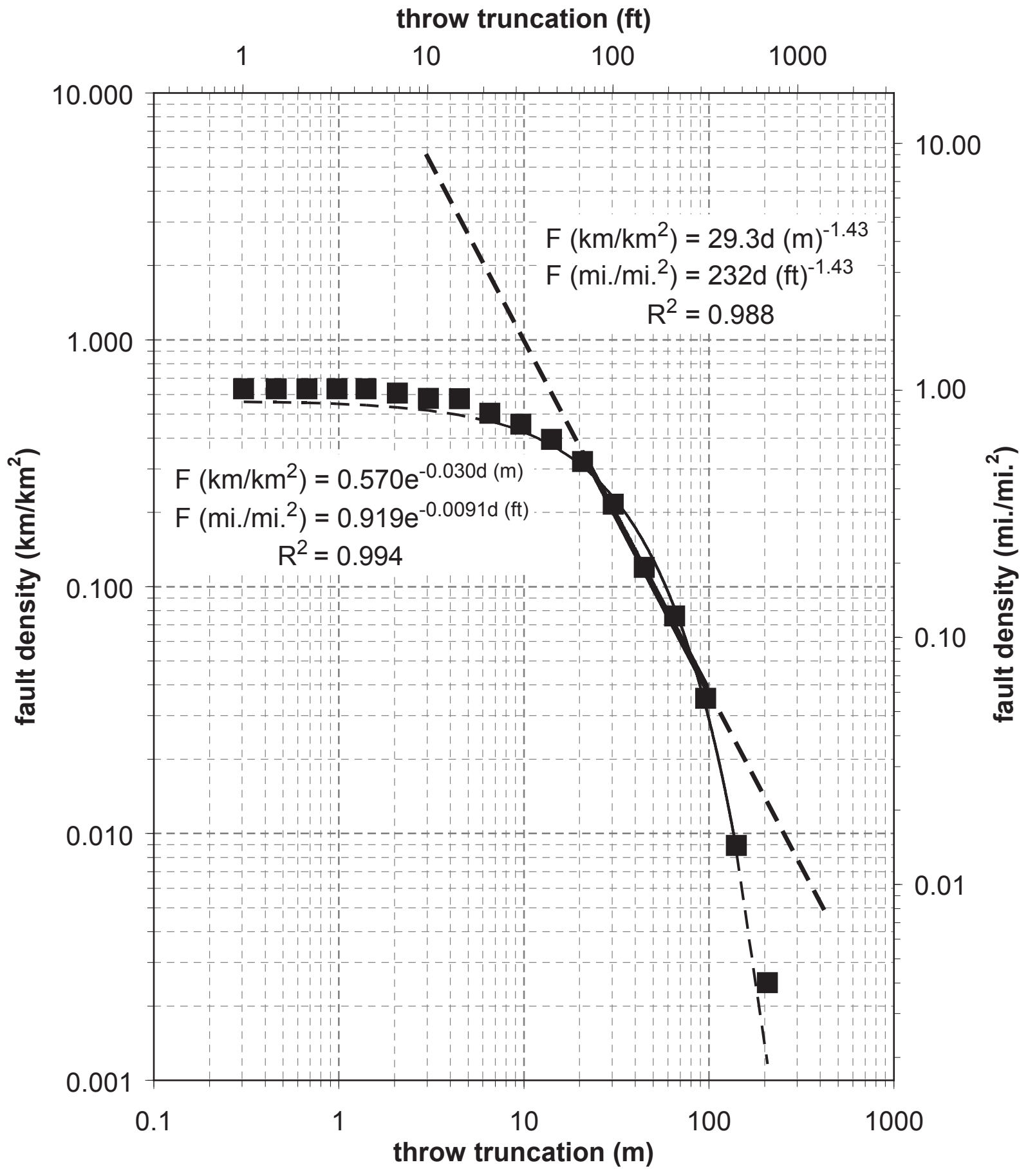

Figure 10 


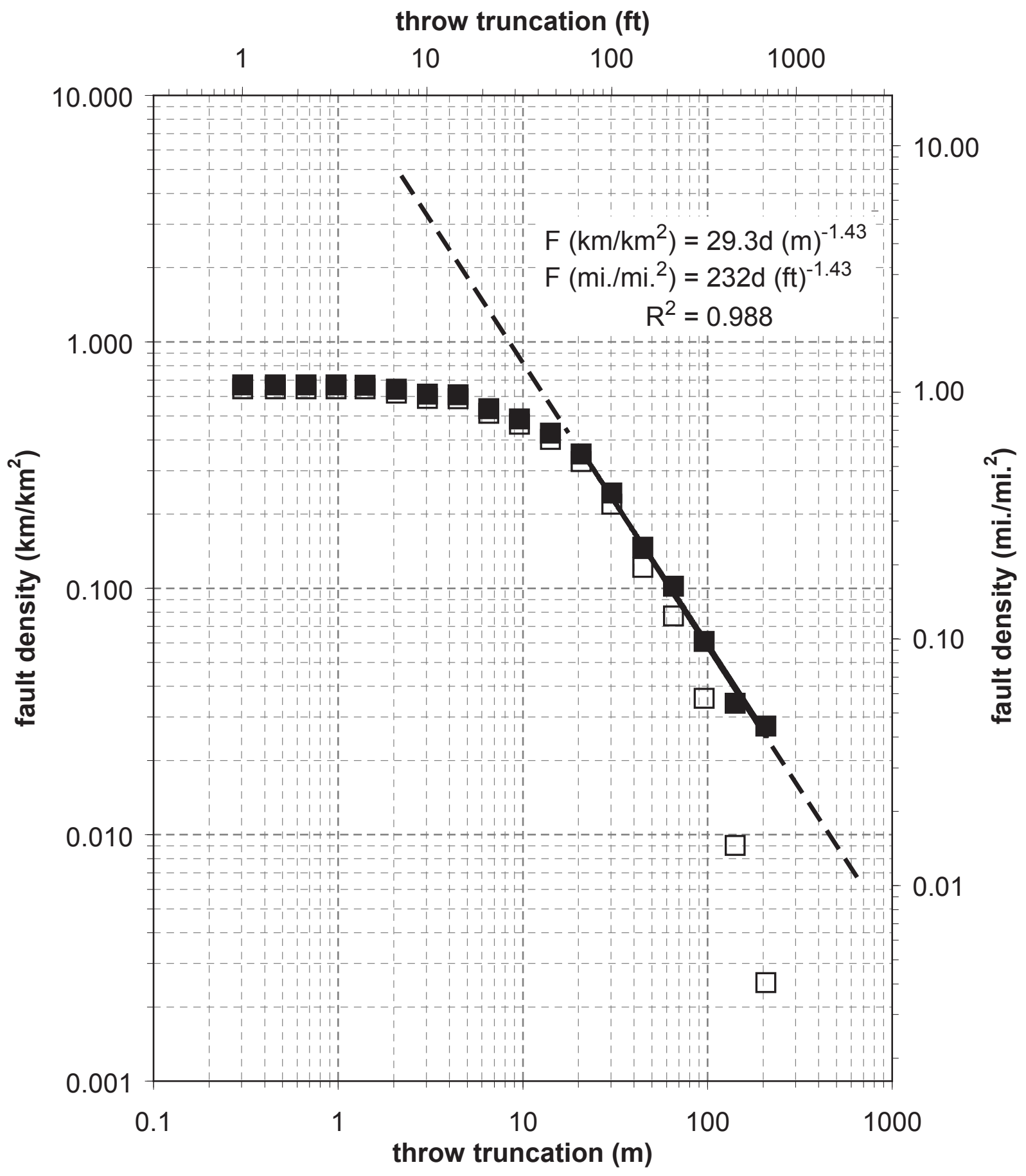

Figure 11 


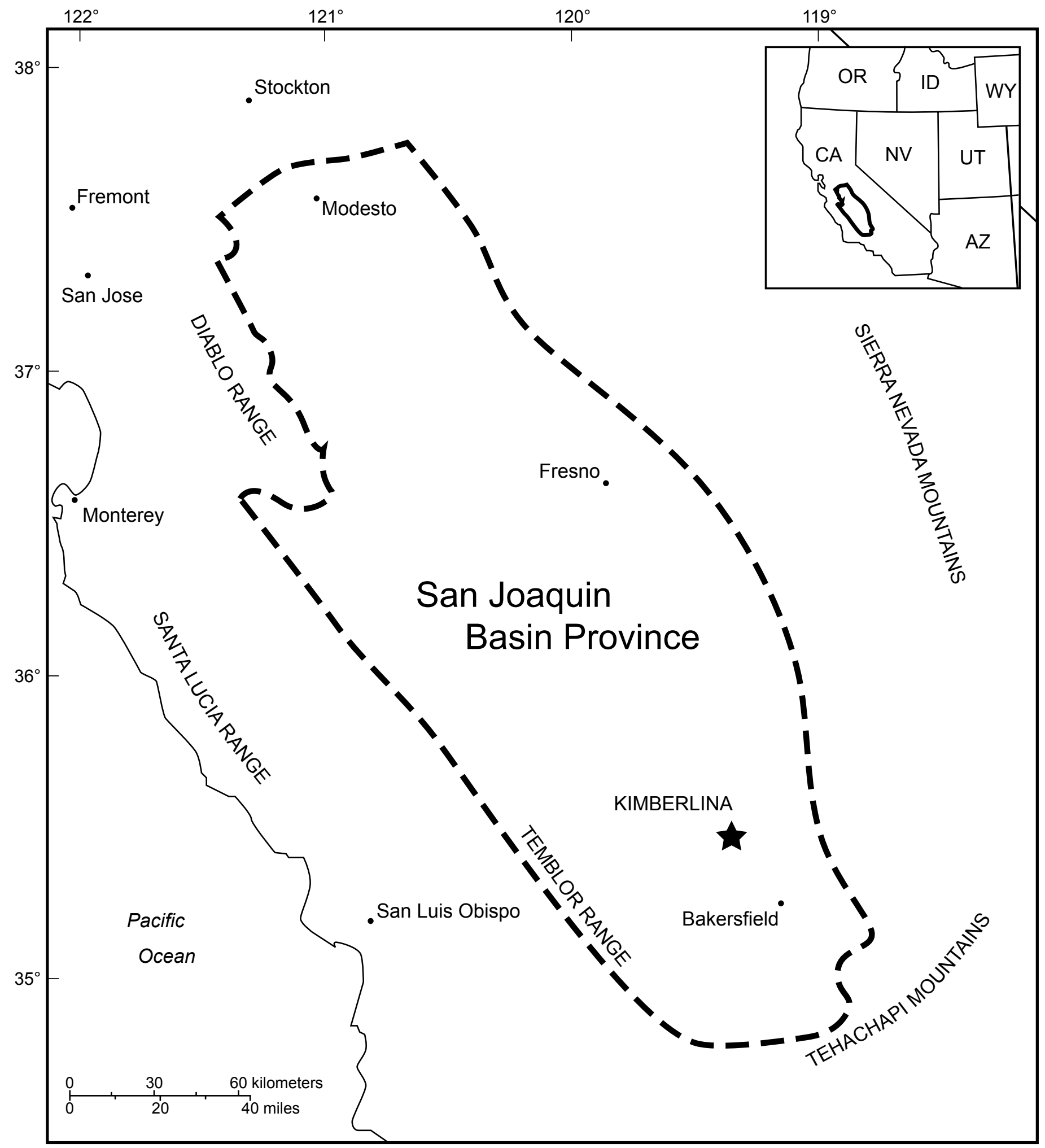

Figure 12 
Appendix 1

field

Bellevue

Bellevue

Bellevue

Bellevue

Bellevue

Bellevue

Bellevue

Bellevue

Bellevue

Bellevue

Bellevue

Bellevue

Bellevue

Bellevue

Bellevue

Bellevue

Bellevue

Bellevue

Bellevue

Bellevue

Bellevue

Bellevue

Bellevue

Bellevue

Bellevue

Bellevue West

Bellevue West

Bellevue West

Bellevue West

Bellevue West

Bellevue West

Bellevue West

Bellevue West

Bellevue West

Bellevue West

Bellevue West

Bellevue West

Bellevue West

Bellevue West

Bellevue West

Bellevue West

Bellevue West

Bellevue West

Bellevue West

Bellevue West

Bellevue West

Bellevue West

Bellevue West

$\begin{array}{cc}\text { vertical length } \\ \text { offset } & (\mathrm{ft})\end{array}$ strike note

number segment start end

$\begin{array}{cccccc}1 & 1 & 35 & 65 & 870 & 9 \\ 1 & 2 & 65 & 110 & 1038 & 8 \\ 1 & 3 & 110 & 165 & 732 & 6 \\ 1 & 4 & 165 & 240 & 534 & 8 \\ 1 & 5 & 240 & 295 & 656 & 6 \\ 1 & 6 & 295 & 345 & 824 & 10 \\ 1 & 7 & 345 & 380 & 778 & 8 \\ 1 & 8 & 380 & 395 & 763 & 8 \\ 1 & 9 & 395 & 330 & 763 & 9 \\ 1 & 10 & 330 & 270 & 961 & 9 \\ 1 & 11 & 330 & 320 & 1083 & 4 \\ 1 & 12 & 320 & 255 & 1190 & 4 \\ 1 & 13 & 255 & 165 & 870 & 0 \\ 1 & 14 & 165 & 125 & 4059 & 179 \\ 2 & 1 & 20 & 20 & 748 & 132 \\ 2 & 2 & 20 & 30 & 2243 & 123 \\ 2 & 3 & 30 & 75 & 626 & 123 \\ 2 & 4 & 75 & 75 & 794 & 117 \\ 2 & 5 & 75 & 60 & 977 & 114 \\ 2 & 6 & 60 & 75 & 977 & 115 \\ 2 & 7 & 75 & 60 & 687 & 108 \\ 3 & 1 & 10 & 40 & 1862 & 140 \\ 3 & 2 & 40 & 45 & 1877 & 139 \\ 3 & 3 & 45 & 45 & 2960 & 141 \\ 3 & 4 & 45 & 15 & 1801 & 140 \\ 1 & 1 & & & 2071 & 142 \\ 1 & 2 & & & 975 & 143 \\ 2 & 1 & 5 & 5 & 457 & 122 \\ 2 & 2 & 5 & 10 & 802 & 120 \\ 2 & 3 & 10 & 5 & 630 & 117 \\ 2 & 4 & 5 & 10 & 640 & 118 \\ 2 & 5 & 10 & 10 & 538 & 112 \\ 2 & 6 & 10 & 10 & 518 & 110 \\ 3 & 1 & 15 & 15 & 711 & 134 \\ 3 & 2 & 15 & 5 & 995 & 134 \\ 3 & 3 & 5 & 5 & 670 & 133 \\ 3 & 4 & 10 & 15 & 721 & 133 \\ 3 & 5 & 15 & 15 & 589 & 131 \\ 3 & 6 & 15 & 10 & 335 & 133 \\ 3 & 7 & 45 & 30 & 294 & 133 \\ 3 & 8 & 30 & 25 & 447 & 131 \\ 3 & 9 & 25 & 25 & 447 & 129 \\ 3 & 10 & 25 & 20 & 284 & 131 \\ 4 & 1 & 20 & 15 & 1472 & 70 \\ 4 & 2 & 15 & 10 & 762 & 68 \\ 4 & 3 & 10 & 15 & 741 & 70 \\ 4 & 4 & 15 & 10 & 914 & 68 \\ 4 & 5 & 25 & 20 & 599 & 67\end{array}$


field

Bellevue West

Bellevue West

Bellevue West

Bellevue West

Bellevue West

Bellevue West

Bellevue West

Bellevue West

Bellevue West

Bellevue West

Bellevue West

Bellevue West

Bellevue West

Bellevue West

Bellevue West

Bellevue West

Bellevue West

Bellevue West

Bellevue West

Calders Corner

Calders Corner

Calders Corner

Calders Corner

Calders Corner

Calders Corner

Calders Corner

Calders Corner

Calders Corner

Calders Corner

Calders Corner

Calders Corner

Calders Corner

Calders Corner

Calders Corner

Calders Corner

Dyer Creek

Fruitvale

Fruitvale

Fruitvale

Fruitvale

Fruitvale

Fruitvale

Fruitvale

Fruitvale

Fruitvale

Fruitvale

Fruitvale

Fruitvale

number segment start end

$\begin{array}{cccccc}4 & 6 & 85 & 65 & 883 & 67 \\ 4 & 7 & 65 & 0 & 1432 & 64 \\ 4 & 8 & 0 & 25 & 843 & 61 \\ 4 & 9 & 25 & 35 & 853 & 58 \\ 5 & 1 & 15 & 15 & 274 & 47 \\ 5 & 2 & 15 & 10 & 467 & 49 \\ 5 & 3 & 10 & 15 & 538 & 46 \\ 5 & 4 & 15 & 15 & 467 & 44 \\ 5 & 5 & 15 & 30 & 650 & 40 \\ 5 & 6 & 30 & 0 & 437 & 38 \\ 5 & 7 & 0 & 30 & 437 & 38 \\ 5 & 8 & 30 & & 619 & 36 \\ 5 & 9 & & & 416 & 33 \\ 6 & 1 & 35 & 60 & 1371 & 141 \\ 6 & 2 & 60 & 75 & 762 & 143 \\ 6 & 3 & 75 & 15 & 640 & 141 \\ 7 & 1 & 65 & 40 & 1310 & 140 \\ 7 & 2 & 40 & 15 & 1706 & 140 \\ 7 & 3 & 30 & 30 & 213 & 140 \\ 1 & 1 & & & 3727 & 136 \\ 1 & 2 & 270 & 205 & 2065 & 134 \\ 1 & 3 & 205 & 100 & 2034 & 124 \\ 1 & 4 & 100 & 65 & 714 & 121 \\ 1 & 5 & & & 2423 & 114 \\ 2 & 1 & & & 3339 & 142 \\ 2 & 2 & 355 & 365 & 1600 & 142 \\ 2 & 3 & 365 & 365 & 699 & 142 \\ 2 & 4 & 365 & 385 & 1227 & 139 \\ 2 & 5 & 385 & 390 & 1072 & 140 \\ 2 & 6 & & & 901 & 141 \\ 3 & 1 & 40 & 45 & 1211 & 60 \\ 3 & 2 & 45 & 45 & 1367 & 56 \\ 3 & 3 & 45 & 180 & 2019 & 55 \\ 4 & 1 & & & 1103 & 61 \\ 4 & 2 & & & 2485 & 55 \\ 1 & 1 & 155 & 155 & 9141 & 143 \\ 1 & 1 & & & 3400 & 155 \\ 1 & 2 & & & 680 & 166 \\ 1 & 3 & 35 & 15 & 3360 & 164 \\ 1 & 4 & 10 & 10 & 560 & 170 \\ 1 & 5 & 45 & 25 & 480 & 169 \\ 1 & 6 & 30 & 40 & 3000 & 168 \\ 2 & 1 & & & 2240 & 147 \\ 2 & 2 & & & 1360 & 146 \\ 3 & 1 & 90 & 90 & 1520 & 151 \\ 3 & 2 & 95 & 85 & 3440 & 145 \\ 4 & 1 & 95 & 60 & 3680 & 147 \\ 5 & 1 & 55 & 50 & 1240 & 108\end{array}$


field

Fruitvale

Fruitvale

Fruitvale

Fruitvale

Fruitvale

Fruitvale

Fruitvale

Fruitvale

Fruitvale

Fruitvale

Fruitvale

Fruitvale

Fruitvale

Fruitvale

Fruitvale

Fruitvale

Fruitvale

Fruitvale

Fruitvale

Fruitvale

Fruitvale

Fruitvale

Fruitvale

Fruitvale

Fruitvale

Fruitvale

Fruitvale

Fruitvale

Fruitvale

Fruitvale

Fruitvale

Fruitvale

Fruitvale

Fruitvale

Fruitvale

Fruitvale

Fruitvale

Fruitvale

Fruitvale

Fruitvale

Fruitvale

Fruitvale

Fruitvale

Fruitvale

Fruitvale

Fruitvale

Fruitvale

Fruitvale

apparent

fault vertical

$\begin{array}{ccc}\text { vertical length } & \text { strike note } \\ \text { offset } & \text { (ft) }\end{array}$

number segment start end

$\begin{array}{llcccc}5 & 2 & 50 & 35 & 3040 & 110 \\ 6 & 1 & 50 & 35 & 6160 & 143 \\ 7 & 1 & 0 & 55 & 3560 & 123\end{array}$

$\begin{array}{llllll}7 & 2 & 40 & 45 & 1960 & 130\end{array}$

$\begin{array}{llllll}7 & 3 & 10 & 0 & 1800 & 130\end{array}$

$\begin{array}{llllll}7 & 4 & 0 & 5 & 4480 & 132\end{array}$

$\begin{array}{llllll}7 & 5 & 5 & 5 & 1080 & 132\end{array}$

$\begin{array}{llllll}7 & 6 & 20 & 20 & 2960 & 134\end{array}$

$\begin{array}{llllll}7 & 7 & 20 & 20 & 1840 & 141\end{array}$

$\begin{array}{llllll}7 & 8 & 20 & 20 & 1880 & 155\end{array}$

$\begin{array}{llllll}8 & 1 & 35 & 15 & 2560 & 134\end{array}$

$\begin{array}{llllll}8 & 2 & 30 & 30 & 4280 & 134\end{array}$

$\begin{array}{llllll}8 & 3 & 30 & 0 & 5320 & 134\end{array}$

$\begin{array}{llll}9 & 1 & 1680 & 164\end{array}$

$\begin{array}{llllll}9 & 2 & 0 & 0 & 2840 & 164\end{array}$

$\begin{array}{llllll}9 & 3 & 0 & 5 & 2520 & 164\end{array}$

$\begin{array}{llllll}9 & 4 & 5 & 10 & 2280 & 163\end{array}$

$\begin{array}{llllll}9 & 5 & 10 & 0 & 2120 & 162\end{array}$

$\begin{array}{llllll}9 & 6 & 0 & 0 & 3400 & 162\end{array}$

$\begin{array}{llllll}9 & 7 & 0 & 0 & 2840 & 162\end{array}$

$\begin{array}{llllll}10 & 1 & 10 & 10 & 4360 & 96\end{array}$

$\begin{array}{llll}11 & 1 & 1040 & 76\end{array}$

$\begin{array}{llll}12 & 1 & 2320 & 89\end{array}$

$\begin{array}{llll}12 & 2 & 1760 & 86\end{array}$

$\begin{array}{llll}12 & 3 & 480 & 87\end{array}$

$\begin{array}{llll}12 & 4 & 960 & 83\end{array}$

$\begin{array}{llll}13 & 1 & 3720 & 77\end{array}$

$\begin{array}{llllll}14 & 1 & 35 & 35 & 640 & 73\end{array}$

$\begin{array}{llllll}14 & 2 & 35 & 40 & 1160 & 73\end{array}$

$\begin{array}{llllll}14 & 3 & 40 & 30 & 1000 & 73\end{array}$

$\begin{array}{llllll}14 & 4 & 30 & 35 & 1240 & 73\end{array}$

$\begin{array}{llllll}14 & 5 & 35 & 25 & 880 & 73\end{array}$

$\begin{array}{llllll}15 & 1 & 35 & 35 & 920 & 70\end{array}$

$\begin{array}{llllll}15 & 2 & 120 & 40 & 1920 & 72\end{array}$

$\begin{array}{llllll}15 & 3 & 40 & 5 & 2880 & 71\end{array}$

$\begin{array}{llllll}16 & 1 & 115 & 115 & 680 & 70\end{array}$

$\begin{array}{llllll}16 & 2 & 0 & 15 & 1440 & 63\end{array}$

$\begin{array}{llllll}16 & 3 & 50 & 40 & 1360 & 65\end{array}$

$\begin{array}{llllll}16 & 4 & 35 & 35 & 1400 & 64\end{array}$

$\begin{array}{llllll}16 & 5 & 35 & 25 & 1480 & 64\end{array}$

$\begin{array}{llllll}16 & 6 & 25 & 5 & 1400 & 64\end{array}$

$\begin{array}{llllll}16 & 7 & 5 & 0 & 1160 & 65\end{array}$

$\begin{array}{llll}17 & 1 & 3000 & 55\end{array}$

$\begin{array}{llllll}17 & 2 & 45 & 50 & 1600 & 56\end{array}$

$\begin{array}{llllll}17 & 3 & 50 & 55 & 920 & 53\end{array}$

$\begin{array}{llllll}17 & 4 & 15 & 15 & 1160 & 64\end{array}$

$\begin{array}{llllll}17 & 5 & 35 & 25 & 1600 & 64\end{array}$

$\begin{array}{llllll}17 & 6 & 25 & 20 & 800 & 58\end{array}$ 
field

Fruitvale

Fruitvale

Fruitvale

Fruitvale

Fruitvale

Fruitvale

Fruitvale

Fruitvale

Fruitvale

Fruitvale

Fruitvale

Fruitvale

Fruitvale

Fruitvale

Fruitvale

Fruitvale

Fruitvale

Fruitvale

Fruitvale

Fruitvale

Fruitvale

Fruitvale

Fruitvale

Fruitvale

Fruitvale

Fruitvale

Fruitvale

Fruitvale

Fruitvale

Fruitvale

Fruitvale

Fruitvale

Fruitvale

Fruitvale

Fruitvale

Fruitvale

Fruitvale

Fruitvale

Fruitvale

Fruitvale

Fruitvale

Fruitvale

Fruitvale

Fruitvale

Fruitvale

Fruitvale

Fruitvale

Fruitvale

apparent
vertical
offset $\quad \begin{gathered}\text { length } \\ \text { (ft) }\end{gathered}$ strike note

number segment start end

$\begin{array}{llllll}17 & 7 & 60 & 55 & 1120 & 60\end{array}$

$\begin{array}{llllll}17 & 8 & 55 & 30 & 1360 & 60\end{array}$

$\begin{array}{llllll}17 & 9 & 30 & 5 & 1400 & 58\end{array}$

$\begin{array}{llllll}17 & 10 & 40 & 55 & 1040 & 59\end{array}$

$\begin{array}{llllll}18 & 1 & 15 & 0 & 3840 & 58\end{array}$

$\begin{array}{llllll}18 & 2 & 0 & 20 & 2200 & 60\end{array}$

$\begin{array}{llllll}18 & 3 & 20 & 25 & 1120 & 60\end{array}$

$\begin{array}{llllll}18 & 4 & 25 & 0 & 1200 & 63\end{array}$

$\begin{array}{llllll}18 & 5 & 0 & 10 & 1000 & 65\end{array}$

$19 \quad 1 \quad 2840 \quad 54$

$\begin{array}{llllll}19 & 2 & 55 & 55 & 1600 & 54\end{array}$

$\begin{array}{llllll}19 & 3 & 55 & 50 & 840 & 54\end{array}$

$\begin{array}{llllll}19 & 4 & 50 & 50 & 960 & 54\end{array}$

$\begin{array}{llllll}19 & 5 & 50 & 80 & 920 & 54\end{array}$

$\begin{array}{llllll}19 & 6 & 45 & 55 & 1120 & 55\end{array}$

$\begin{array}{llllll}19 & 7 & 55 & 60 & 1640 & 54\end{array}$

$\begin{array}{llllll}19 & 8 & 60 & 50 & 1240 & 53\end{array}$

$\begin{array}{llllll}19 & 9 & 50 & 40 & 720 & 55\end{array}$

$\begin{array}{llllll}19 & 10 & 40 & 0 & 960 & 53\end{array}$

$\begin{array}{llll}20 & 1 & 3240 & 72\end{array}$

$\begin{array}{llllll}20 & 2 & 135 & 100 & 1280 & 72\end{array}$

$\begin{array}{llllll}20 & 3 & 100 & 60 & 1240 & 73\end{array}$

$\begin{array}{llllll}20 & 4 & 60 & 15 & 1560 & 72\end{array}$

$\begin{array}{llllll}20 & 5 & 15 & 0 & 1280 & 73\end{array}$

$\begin{array}{llllll}20 & 6 & 0 & 0 & 1000 & 70\end{array}$

$\begin{array}{llllll}21 & 1 & 0 & 5 & 920 & 41\end{array}$

$\begin{array}{llllll}21 & 2 & 5 & 0 & 1200 & 40\end{array}$

$\begin{array}{llllll}21 & 3 & 0 & 0 & 1000 & 39\end{array}$

$\begin{array}{llll}22 & 1 & 1200 & 0\end{array}$

$\begin{array}{llllll}22 & 2 & 35 & 35 & 2080 & 3\end{array}$

$\begin{array}{llllll}22 & 4 & 35 & 5 & 1400 & 2\end{array}$

$\begin{array}{llllll}22 & 5 & 5 & 0 & 1160 & 3\end{array}$

$\begin{array}{llllll}22 & 6 & 0 & 0 & 560 & 3\end{array}$

$\begin{array}{llllll}23 & 1 & 0 & 45 & 480 & 38\end{array}$

$\begin{array}{llllll}23 & 2 & 45 & 65 & 1240 & 35\end{array}$

$\begin{array}{llllll}23 & 3 & 65 & 20 & 2560 & 36\end{array}$

$23 \quad 4 \quad 2200 \quad 35$

$\begin{array}{llllll}24 & 1 & 0 & 5 & 160 & 30\end{array}$

$\begin{array}{llllll}24 & 2 & 5 & 20 & 960 & 30\end{array}$

$\begin{array}{llllll}24 & 3 & 20 & 35 & 1040 & 30\end{array}$

$\begin{array}{llllll}24 & 4 & 35 & 70 & 1280 & 31\end{array}$

$\begin{array}{llll}25 & 1 & 2480 & 10\end{array}$

$\begin{array}{llllll}25 & 2 & 235 & 250 & 1040 & 8\end{array}$

$\begin{array}{llllll}25 & 3 & 125 & 110 & 2720 & 0\end{array}$

$\begin{array}{llllll}25 & 4 & 180 & 120 & 1760 & 0\end{array}$

$\begin{array}{llllll}25 & 5 & 120 & 105 & 1280 & 0\end{array}$

$\begin{array}{llllll}25 & 6 & 105 & 85 & 2160 & 0\end{array}$

$\begin{array}{llllll}25 & 7 & 65 & 10 & 3120 & 0\end{array}$ 
field

Fruitvale

Fruitvale

Fruitvale

Fruitvale

Fruitvale

Goosloo

Goosloo

Goosloo

Goosloo

Goosloo

Goosloo

Goosloo

Goosloo

Goosloo

Goosloo

Goosloo

Goosloo

Goosloo

Goosloo

Goosloo

Goosloo

Goosloo

Greeley

Greeley

Greeley

Greeley

Greeley

Greeley

Greeley

Greeley

Greeley

Greeley

Greeley

Jasmin, West

Jasmin, West

Jasmin, West

Jasmin, West

fault

apparent

$\begin{array}{cc}\text { vertical length } \\ \text { offset } & (\mathrm{ft})\end{array}$ strike note

number segment start end

\begin{tabular}{|c|c|c|c|c|c|c|}
\hline 25 & 8 & 0 & 0 & 2080 & 169 & \\
\hline 26 & 1 & 125 & 85 & 1440 & 24 & \\
\hline 26 & 2 & 855 & 120 & 1480 & 28 & \\
\hline 26 & 3 & 120 & 165 & 1360 & 27 & \\
\hline 26 & 4 & & & 1920 & 28 & \\
\hline 1 & 1 & & & 6065 & 140 & \\
\hline 1 & 2 & 145 & 105 & 1542 & 136 & \\
\hline 1 & 3 & 105 & 135 & 1897 & 137 & \\
\hline 1 & 4 & 135 & 150 & 1042 & 136 & \\
\hline 1 & 5 & 50 & 90 & 1230 & 134 & \\
\hline 1 & 6 & 90 & 140 & 1938 & 133 & \\
\hline 1 & 7 & 140 & 175 & 2147 & 137 & \\
\hline 1 & 8 & & & 1167 & 141 & \\
\hline 1 & 9 & & & 2960 & 164 & \\
\hline 2 & 1 & & & 1459 & 129 & \\
\hline 2 & 2 & & & 1396 & 127 & \\
\hline 2 & 3 & 40 & 20 & 1897 & 125 & \\
\hline 2 & 4 & 60 & 30 & 2605 & 125 & \\
\hline 2 & 5 & 0 & 15 & 2814 & 128 & \\
\hline 2 & 6 & 25 & 20 & 1605 & 131 & \\
\hline 2 & 7 & & & 1459 & 135 & \\
\hline 3 & 1 & 40 & 100 & 2647 & 25 & \\
\hline 1 & 1 & & & 4284 & 146 & right lateral \\
\hline 1 & 2 & 80 & 130 & 1419 & 148 & right lateral \\
\hline 1 & 3 & 130 & 90 & 928 & 144 & right lateral \\
\hline 1 & 4 & 90 & 70 & 682 & 145 & right lateral \\
\hline 1 & 5 & 70 & 50 & 2756 & 144 & right lateral \\
\hline 1 & 6 & 50 & 40 & 1555 & 143 & right lateral \\
\hline 1 & 7 & 40 & 100 & 3465 & 143 & right lateral \\
\hline 1 & 8 & & & 12061 & 143 & right lateral \\
\hline 2 & 1 & & & 3274 & 24 & \\
\hline 2 & 2 & & & 2565 & 14 & \\
\hline 2 & 3 & & & 2838 & 3 & \\
\hline 1 & 1 & & & 1200 & 162 & \\
\hline 1 & 2 & 75 & 80 & 1706 & 162 & \\
\hline 1 & 3 & 80 & 70 & 1020 & 162 & \\
\hline 1 & 4 & 70 & 65 & 1191 & 162 & \\
\hline 1 & 5 & 65 & 70 & 1309 & 162 & \\
\hline 1 & 6 & & & 614 & 162 & \\
\hline 1 & 1 & & & 4718 & 133 & \\
\hline 1 & 2 & & & 1377 & 141 & \\
\hline 1 & 3 & & & 1722 & 153 & \\
\hline 1 & 4 & & & 3030 & 164 & \\
\hline 1 & 5 & & & 3857 & 176 & \\
\hline 1 & 6 & & & 5751 & 1 & \\
\hline 1 & 7 & 95 & 70 & 2720 & 14 & \\
\hline 1 & 8 & 70 & 50 & 1240 & 29 & \\
\hline 1 & 9 & 50 & 20 & 12 & 28 & \\
\hline
\end{tabular}


field

Kern Front

Kern Front

Kern Front

Kern Front

Kern Front

Kern Front

Kern Front

Kern Front

Kern Front

Kern Front

Kern Front

Kern Front

Kern Front

Kern Front

Kern Front

Kern Front

Kern Front

Kern Front

Kern Front

Kern Front

Kern Front

Kern Front

Kern Front

Kern Front

Kern Front

Kern Front

Kern Front

Kern Front

Kern Front

Kern Front

Kern Front

Kern Front

Kern River

Kern River

Kern River

Kern River

Kern River

Kern River

Kern River

Kern River

Kern River

Kern River

Kern River

Kern River

Kern River

Kern River

Kern River

Kern River

apparent

fault

vertical

offset

length

(ft)

strike

note

number segment start end

\begin{tabular}{|c|c|c|c|c|c|c|}
\hline 1 & 10 & 20 & 0 & 1894 & 39 & \\
\hline 2 & 1 & 0 & 10 & 895 & 32 & \\
\hline 2 & 2 & 10 & 20 & 1377 & 37 & \\
\hline 2 & 3 & 20 & 30 & 2101 & 43 & \\
\hline 3 & 1 & & & 2824 & 3 & \\
\hline 3 & 2 & 40 & 10 & 2789 & 179 & \\
\hline 3 & 3 & 10 & 30 & 2204 & 172 & \\
\hline 3 & 4 & 30 & 0 & 1791 & 159 & \\
\hline 4 & 1 & 0 & 25 & 826 & 59 & \\
\hline 4 & 2 & 25 & 0 & 689 & 60 & \\
\hline 5 & 1 & & & 2169 & 31 & \\
\hline 5 & 2 & 30 & 0 & 1653 & 28 & \\
\hline 5 & 3 & 0 & 30 & 2307 & 20 & \\
\hline 5 & 4 & 30 & 40 & 1377 & 34 & \\
\hline 5 & 5 & 40 & 20 & 1722 & 27 & \\
\hline 5 & 6 & 20 & 0 & 895 & 19 & \\
\hline 6 & 1 & & & 2479 & 43 & \\
\hline 6 & 2 & 85 & 120 & 1756 & 52 & \\
\hline 6 & 3 & 120 & 120 & 1102 & 36 & \\
\hline 6 & 4 & 120 & 70 & 1756 & 26 & \\
\hline 6 & 5 & 70 & 20 & 2893 & 28 & \\
\hline 6 & 6 & 20 & 0 & 1963 & 48 & \\
\hline 7 & 1 & 0 & 5 & 1997 & 50 & \\
\hline 7 & 2 & 5 & 5 & 1515 & 42 & \\
\hline 7 & 3 & 5 & 5 & 1653 & 43 & \\
\hline 7 & 4 & 5 & 0 & 1240 & 51 & \\
\hline 8 & 1 & & & 2238 & 29 & \\
\hline 8 & 2 & & & 4201 & 20 & \\
\hline 8 & 3 & & & 2169 & 8 & \\
\hline 8 & 4 & & & 2101 & 176 & \\
\hline 8 & 5 & & & 1756 & 165 & \\
\hline 8 & 6 & & & 2101 & 157 & \\
\hline 1 & 1 & & & 3174 & 170 & \\
\hline 1 & 2 & & & 2527 & 175 & \\
\hline 1 & 3 & & & 2106 & 89 & \\
\hline 1 & 4 & & & 1684 & 7 & \\
\hline 1 & 5 & & & 1846 & 20 & \\
\hline 2 & 1 & & & 1749 & 138 & \\
\hline 2 & 2 & & & 2462 & 144 & \\
\hline 3 & 1 & & & 1846 & 136 & \\
\hline 3 & 2 & & & 2106 & 137 & \\
\hline 4 & 1 & 100 & 85 & 3401 & 70 & \\
\hline 4 & 2 & & & 4470 & 74 & \\
\hline 5 & 1 & & & 2235 & 104 & China Fault Zone \\
\hline 5 & 2 & & & 3920 & 100 & China Fault Zone \\
\hline 5 & 3 & & & 1814 & 97 & China Fault Zone \\
\hline 5 & 4 & 60 & 100 & 2494 & 91 & China Fault Zone \\
\hline 5 & 5 & 100 & 135 & 2786 & 94 & China Fault Zone \\
\hline
\end{tabular}


field

Kern River

Kern River

Kern River

McClung

McClung

McClung

McClung

McClung

McClung

McClung

McClung

McClung

McClung

McClung

McClung

McClung

McClung

McClung

McClung

McClung

McClung

McClung

McClung

McClung

Mount Poso

Mount Poso

Mount Poso

Mount Poso

Mount Poso

Mount Poso

Mount Poso

Mount Poso

Mount Poso

Mount Poso

Mount Poso

Mount Poso

Mount Poso

Mount Poso

Mount Poso

Mount Poso

Mount Poso

Mount Poso

Mount Poso

Mount Poso

Mount Poso

Mount Poso

Mount Poso

Mount Poso apparent

$\begin{array}{cc}\begin{array}{c}\text { vertical length } \\ \text { offset }\end{array} & (\mathrm{ft})\end{array}$ strike note

number segment start end

$\begin{array}{ccccccl}5 & 6 & 135 & 160 & 2073 & 95 & \text { China Fault Zone } \\ 5 & 7 & 60 & 40 & 2235 & 99 & \text { China Fault Zone } \\ 5 & 8 & & & 2235 & 103 & \text { China Fault Zone } \\ 1 & 1 & & & 2335 & 69 & \\ 2 & 1 & 40 & 15 & 719 & 140 & \\ 2 & 2 & 15 & 60 & 609 & 140 & \end{array}$

$\begin{array}{llllll}2 & 3 & 60 & 70 & 770 & 140\end{array}$

$\begin{array}{llllll}2 & 4 & 70 & 5 & 1117 & 141\end{array}$

$\begin{array}{llllll}2 & 5 & 15 & 20 & 1312 & 140\end{array}$

$\begin{array}{llllll}2 & 6 & 20 & 20 & 1532 & 141\end{array}$

$\begin{array}{llllll}2 & 7 & 20 & 20 & 1591 & 140\end{array}$

$\begin{array}{llllll}3 & 1 & 80 & 45 & 1100 & 141\end{array}$

$\begin{array}{llllll}3 & 2 & 45 & 65 & 1650 & 140\end{array}$

$\begin{array}{llllll}3 & 3 & 80 & 80 & 85 & 140\end{array}$

$\begin{array}{llllll}3 & 4 & 45 & 25 & 618 & 141\end{array}$

$\begin{array}{llllll}3 & 5 & 25 & 15 & 643 & 140\end{array}$

$\begin{array}{llllll}3 & 6 & 15 & 15 & 1159 & 140\end{array}$

$\begin{array}{llllll}3 & 7 & 15 & 15 & 1134 & 139\end{array}$

$\begin{array}{llllll}3 & 8 & 15 & 30 & 1345 & 140\end{array}$

$\begin{array}{llllll}4 & 1 & 10 & 45 & 626 & 59\end{array}$

$\begin{array}{llllll}5 & 1 & 15 & 10 & 762 & 47\end{array}$

$\begin{array}{llllll}5 & 2 & 10 & 15 & 542 & 45\end{array}$

$\begin{array}{llllll}5 & 3 & 15 & 20 & 1168 & 43\end{array}$

$\begin{array}{lllll}5 & 4 & & 20 & 1168\end{array}$

$\begin{array}{llllll}1 & 1 & 130 & 130 & 2459 & 144\end{array}$

$\begin{array}{llllll}1 & 2 & 130 & 130 & 2317 & 147\end{array}$

$\begin{array}{llllll}1 & 3 & 80 & 75 & 2128 & 149\end{array}$

$\begin{array}{llllll}1 & 4 & 75 & 65 & 2932 & 150\end{array}$

$\begin{array}{llllll}2 & 1 & 20 & 20 & 2317 & 97\end{array}$

$\begin{array}{llllll}2 & 2 & 20 & 10 & 1560 & 106\end{array}$

$\begin{array}{llllll}2 & 3 & 10 & 5 & 1702 & 115\end{array}$

$\begin{array}{llllll}2 & 4 & 5 & 25 & 1749 & 124\end{array}$

$\begin{array}{llllll}2 & 5 & 25 & 30 & 1277 & 127\end{array}$

$\begin{array}{llllll}2 & 6 & 30 & 40 & 1324 & 132\end{array}$

$\begin{array}{llllll}3 & 1 & 80 & 80 & 2033 & 141\end{array}$

$\begin{array}{llllll}3 & 2 & 80 & 75 & 1277 & 144\end{array}$

$\begin{array}{llllll}3 & 3 & 65 & 75 & 2459 & 145\end{array}$

$\begin{array}{llllll}3 & 4 & 125 & 100 & 1608 & 145\end{array}$

$\begin{array}{llllll}3 & 5 & 125 & 140 & 4303 & 146\end{array}$

$\begin{array}{llllll}3 & 6 & 220 & 205 & 2080 & 162\end{array}$

$\begin{array}{llllll}3 & 7 & 240 & 240 & 567 & 167\end{array}$

$\begin{array}{llllll}3 & 8 & 250 & 250 & 662 & 168\end{array}$

$\begin{array}{llllll}3 & 9 & 265 & 230 & 993 & 4\end{array}$

$\begin{array}{llllll}3 & 10 & 230 & 170 & 2411 & 166\end{array}$

$\begin{array}{llllll}3 & 11 & 170 & 140 & 1135 & 152\end{array}$

$\begin{array}{llllll}3 & 12 & 220 & 240 & 2695 & 118\end{array}$

$\begin{array}{llllll}3 & 13 & 410 & 410 & 993 & 164\end{array}$

$\begin{array}{llllll}3 & 14 & 410 & 405 & 993 & 175\end{array}$ 
field

Mount Poso

Mount Poso

Mount Poso

Mount Poso

Mount Poso

Mount Poso

Mount Poso

Mount Poso

Mount Poso

Mount Poso

Mount Poso

Mount Poso

Mount Poso

Mount Poso

Mount Poso

Mount Poso

Mount Poso

Mount Poso

Mount Poso

Mount Poso

Mount Poso

Mount Poso

Mount Poso

Mount Poso

Mount Poso

Mount Poso

Mount Poso

Mount Poso

Mount Poso

Mount Poso

Mount Poso

Mount Poso

Mount Poso

Mount Poso

Mount Poso

Mount Poso

Mount Poso

Mount Poso

Mount Poso

Mount Poso

Mount Poso

Mount Poso

Mount Poso

Mount Poso

Mount Poso

Mount Poso

Mount Poso

Mount Poso apparent

$\begin{array}{cc}\begin{array}{c}\text { vertical length } \\ \text { offset }\end{array} & (\mathrm{ft}) \\ & \end{array}$

number segment start end

$\begin{array}{llllll}3 & 16 & 400 & 405 & 1749 & 143\end{array}$

$\begin{array}{llllll}3 & 17 & 405 & 405 & 1371 & 156\end{array}$

$\begin{array}{llllll}3 & 18 & 405 & 410 & 1135 & 168\end{array}$

$\begin{array}{llllll}3 & 19 & 410 & 415 & 1513 & 175\end{array}$

$\begin{array}{llllll}3 & 20 & 415 & 415 & 615 & 160\end{array}$

$\begin{array}{llllll}3 & 21 & 120 & 110 & 1040 & 135\end{array}$

$\begin{array}{llllll}3 & 22 & 110 & 105 & 662 & 131\end{array}$

$\begin{array}{llllll}3 & 23 & 85 & 75 & 3073 & 147\end{array}$

$\begin{array}{llllll}3 & 24 & 75 & 80 & 1939 & 148\end{array}$

$\begin{array}{llllll}3 & 25 & 80 & 95 & 5012 & 141\end{array}$

$\begin{array}{llllll}3 & 26 & 95 & 95 & 1749 & 139\end{array}$

$\begin{array}{llllll}3 & 27 & 50 & 65 & 2080 & 136\end{array}$

$\begin{array}{llllll}3 & 28 & 65 & 70 & 804 & 126\end{array}$

$\begin{array}{llllll}4 & 1 & 55 & 55 & 2553 & 126\end{array}$

$\begin{array}{llllll}4 & 2 & 55 & 45 & 1844 & 127\end{array}$

$\begin{array}{llllll}4 & 3 & 15 & 75 & 2742 & 127\end{array}$

$\begin{array}{llllll}4 & 4 & 75 & 65 & 1324 & 130\end{array}$

$\begin{array}{llllll}4 & 5 & 55 & 35 & 1608 & 133\end{array}$

$\begin{array}{llllll}4 & 6 & 35 & 20 & 1844 & 153\end{array}$

$\begin{array}{llllll}4 & 7 & 20 & 10 & 1040 & 134\end{array}$

$\begin{array}{llllll}4 & 8 & 10 & 10 & 1939 & 133\end{array}$

$\begin{array}{llllll}4 & 9 & 20 & 5 & 1277 & 129\end{array}$

$\begin{array}{llllll}4 & 10 & 5 & 0 & 2175 & 130\end{array}$

$\begin{array}{llllll}5 & 1 & 60 & 60 & 4208 & 179\end{array}$

$\begin{array}{llllll}6 & 1 & 105 & 95 & 2695 & 136\end{array}$

$\begin{array}{llllll}6 & 2 & 120 & 105 & 3499 & 136\end{array}$

$\begin{array}{llllll}7 & 1 & 10 & 10 & 1324 & 175\end{array}$

$\begin{array}{llllll}7 & 2 & 195 & 215 & 2222 & 179\end{array}$

$\begin{array}{llllll}8 & 1 & 50 & 50 & 1844 & 117\end{array}$

$\begin{array}{llllll}8 & 2 & 50 & 40 & 1371 & 110\end{array}$

$\begin{array}{llllll}8 & 3 & 40 & 25 & 1040 & 111\end{array}$

$\begin{array}{llllll}8 & 4 & 25 & 5 & 1182 & 119\end{array}$

$\begin{array}{llllll}8 & 5 & 85 & 20 & 1088 & 129\end{array}$

$\begin{array}{llllll}8 & 6 & 20 & 20 & 1797 & 144\end{array}$

$\begin{array}{llllll}8 & 7 & 20 & 30 & 1371 & 104\end{array}$

$\begin{array}{llllll}9 & 1 & 90 & 40 & 3357 & 157\end{array}$

$\begin{array}{llllll}9 & 2 & 50 & 50 & 473 & 154\end{array}$

$\begin{array}{llllll}9 & 3 & 15 & 15 & 1135 & 160\end{array}$

$\begin{array}{llllll}9 & 4 & 30 & 30 & 473 & 158\end{array}$

$\begin{array}{llllll}10 & 1 & 45 & 70 & 4114 & 0\end{array}$

$\begin{array}{llllll}10 & 2 & 100 & 80 & 1749 & 0\end{array}$

$\begin{array}{llllll}11 & 1 & 70 & 100 & 2837 & 117\end{array}$

$\begin{array}{llllll}12 & 1 & 140 & 135 & 1939 & 114\end{array}$

$\begin{array}{llllll}12 & 2 & 50 & 65 & 1466 & 114\end{array}$

$\begin{array}{llllll}12 & 3 & 65 & 70 & 1702 & 116\end{array}$

$\begin{array}{llllll}12 & 4 & 70 & 80 & 1891 & 116\end{array}$

$\begin{array}{llllll}13 & 1 & 15 & 20 & 615 & 163\end{array}$ 
field

Mount Poso

Mount Poso

Mount Poso

Mount Poso

Mount Poso

Mount Poso

Mount Poso

Mount Poso

Mount Poso

Mount Poso

Mount Poso

Mount Poso

Mount Poso

Mount Poso

Mount Poso

Mount Poso

Mount Poso

Mount Poso

Mount Poso

Mount Poso

Mount Poso

Mount Poso

Mount Poso

Mount Poso

Mount Poso

Mount Poso

Mount Poso

Mount Poso

Mount Poso

Mount Poso

Mount Poso

Mount Poso

Mount Poso

Mount Poso

Mount Poso

Mount Poso

Mount Poso

Mount Poso

Mount Poso

Mount Poso

Mount Poso

Mount Poso

Mount Poso

Mount Poso

Mount Poso

Mount Poso

Mount Poso

Mount Poso apparent

$\begin{array}{cc}\begin{array}{c}\text { vertical length } \\ \text { offset }\end{array} & (\mathrm{ft}) \\ & \end{array}$

number segment start end

13

13

13

13

$14 \quad 1$

$14 \quad 2$

$14 \quad 3$

14

14

14

14

14

$14 \quad 10$

$14 \quad 11$

$14 \quad 12$

$14 \quad 13$

$14 \quad 14$

$14 \quad 15$

$14 \quad 16$

14

14

14

14

15

15

15

16

16

16

16

16

16

16

16

16

16

16

16

17

17

17

17

17

17

18

18

$90 \quad 115$

$\begin{array}{ll}115 & 125\end{array}$

$125 \quad 150$

150160

$160 \quad 170$

$\begin{array}{llll}90 & 95 & 1608 & 122\end{array}$

$\begin{array}{llll}95 & 95 & 1088 & 131\end{array}$

$\begin{array}{llll}95 & 90 & 1560 & 145\end{array}$

$\begin{array}{llll}90 & 100 & 1324 & 155\end{array}$

$\begin{array}{llll}100 & 110 & 1466 & 162\end{array}$

$\begin{array}{llll}110 & 140 & 3877 & 168\end{array}$

$\begin{array}{llll}140 & 155 & 1797 & 163\end{array}$

$\begin{array}{llll}155 & 165 & 1277 & 157\end{array}$

$\begin{array}{llll}165 & 150 & 3263 & 155\end{array}$

$\begin{array}{llll}150 & 145 & 851 & 152\end{array}$

$\begin{array}{llll}145 & 130 & 1891 & 141\end{array}$

$\begin{array}{llll}130 & 170 & 2932 & 135\end{array}$

$\begin{array}{llll}170 & 165 & 2884 & 140\end{array}$

$\begin{array}{llll}165 & 165 & 1182 & 146\end{array}$

$\begin{array}{llll}165 & 140 & 2175 & 148\end{array}$

$\begin{array}{llll}140 & 105 & 3594 & 155\end{array}$

$\begin{array}{llll}35 & 30 & 898 & 156\end{array}$

$\begin{array}{llll}40 & 45 & 2459 & 158\end{array}$

$\begin{array}{llll}45 & 55 & 3546 & 162\end{array}$

$\begin{array}{llll}130 & 100 & 1277 & 113\end{array}$

$\begin{array}{llll}100 & 85 & 1891 & 120\end{array}$

$\begin{array}{llll}85 & 95 & 2128 & 126\end{array}$

$\begin{array}{llll}50 & 55 & 2742 & 157\end{array}$

$\begin{array}{llll}40 & 20 & 993 & 147\end{array}$

$\begin{array}{llll}175 & 150 & 2270 & 144\end{array}$

$\begin{array}{llll}125 & 85 & 4114 & 145\end{array}$

$\begin{array}{llll}85 & 75 & 3263 & 146\end{array}$

$\begin{array}{llll}75 & 65 & 2175 & 148\end{array}$

$\begin{array}{llll}65 & 110 & 4870 & 152\end{array}$

$\begin{array}{llll}110 & 130 & 5059 & 151\end{array}$

$\begin{array}{llll}130 & 150 & 4587 & 152\end{array}$

$\begin{array}{llll}150 & 175 & 4681 & 152\end{array}$

$1702 \quad 153$

$2506 \quad 158$

$\begin{array}{llll}155 & 130 & 1939 & 117\end{array}$

$\begin{array}{llll}130 & 70 & 1608 & 133\end{array}$

$\begin{array}{llll}70 & 50 & 3215 & 147\end{array}$

$\begin{array}{llll}50 & 65 & 2080 & 136\end{array}$

$\begin{array}{llll}65 & 120 & 2175 & 131\end{array}$

$\begin{array}{llll}120 & 130 & 946 & 131\end{array}$

$\begin{array}{llll}0 & 10 & 2884 & 145\end{array}$

$\begin{array}{llll}10 & 0 & 2932 & 145\end{array}$ 
field

Mount Poso

Mount Poso

Mount Poso

Mount Poso

Mount Poso

Mount Poso

Mount Poso

Mount Poso

Mount Poso

Mount Poso

Mount Poso

Mount Poso

Mount Poso

Mount Poso

Mount Poso

Mount Poso

Mount Poso

Mount Poso

Mount Poso

Mount Poso

Mount Poso

Mount Poso

Mount Poso

Mount Poso

Mount Poso

Mount Poso

Mount Poso

Mount Poso

Mount Poso

Mount Poso

Mount Poso

Mount Poso

Mount Poso

Mount Poso

Mount Poso

Mount Poso

Mount Poso

Mount Poso

Mount Poso

Mount Poso

Mount Poso

Mount Poso

Mount Poso

Mount Poso

Mount Poso

Mount Poso

Mount Poso

Mount Poso apparent

$\begin{array}{cc}\begin{array}{c}\text { vertical length } \\ \text { offset }\end{array} & (\mathrm{ft})\end{array}$ strike note

number segment start end

$\begin{array}{cccccc}18 & 3 & 0 & 15 & 804 & 150 \\ 18 & 4 & 15 & 45 & 1891 & 154 \\ 18 & 5 & 45 & 65 & 1088 & 146 \\ 18 & 6 & 65 & 90 & 946 & 138 \\ 18 & 7 & 90 & 120 & 1324 & 135 \\ 18 & 8 & 120 & 130 & 1419 & 142 \\ 18 & 9 & 0 & 0 & 1419 & 148 \\ 19 & 1 & 55 & 50 & 615 & 0 \\ 19 & 2 & 50 & 40 & 1277 & 0 \\ 20 & 1 & 0 & 35 & 4303 & 148 \\ 20 & 2 & 35 & 40 & 2222 & 152 \\ 20 & 3 & 40 & 40 & 1419 & 140 \\ 20 & 4 & 40 & 55 & 1371 & 133 \\ 20 & 5 & 55 & 65 & 2033 & 124 \\ 20 & 6 & 65 & 60 & 2222 & 129 \\ 20 & 7 & 30 & 30 & 1513 & 142 \\ 20 & 8 & 30 & 50 & 1891 & 152 \\ 20 & 9 & 255 & 240 & 2411 & 157 \\ 20 & 10 & 240 & 170 & 6478 & 164 \\ 20 & 11 & 115 & 115 & 4634 & 163 \\ 21 & 1 & 35 & 35 & 378 & 98 \\ 21 & 2 & 95 & 100 & 2601 & 99 \\ 21 & 3 & 75 & 80 & 615 & 102 \\ 21 & 4 & 130 & 90 & 2506 & 110 \\ 21 & 5 & 90 & 80 & 1513 & 119 \\ 21 & 6 & 120 & 65 & 1229 & 129 \\ 21 & 7 & 65 & 105 & 3026 & 131 \\ 21 & 8 & 105 & 105 & 3121 & 138 \\ 21 & 9 & 105 & 95 & 3688 & 145 \\ 21 & 10 & 95 & 90 & 3641 & 144 \\ 21 a & 1 & 0 & 15 & 1229 & 123 \\ 21 \mathrm{a} & 2 & 15 & 50 & 2411 & 128 \\ 21 \mathrm{a} & 3 & 50 & 45 & 2459 & 134 \\ 21 \mathrm{a} & 4 & 45 & 30 & 2080 & 139 \\ 22 & 1 & 10 & 10 & 1182 & 104 \\ 22 & 2 & 10 & 10 & 1324 & 110 \\ 22 & 3 & 45 & 25 & 1466 & 120 \\ 22 & 4 & 25 & 15 & 1655 & 120 \\ 22 & 5 & 15 & 15 & 1891 & 129 \\ 22 & 6 & 15 & 30 & 1797 & 135 \\ 22 & 7 & 230 & 220 & 2222 & 140 \\ 22 & 8 & 220 & 190 & 662 & 145 \\ 22 & 9 & 190 & 185 & 3641 & 142 \\ 22 & 10 & 185 & 190 & 3404 & 141 \\ 22 & 11 & 345 & 350 & 3073 & 140 \\ 22 & 12 & 350 & 350 & 3925 & 138 \\ 23 & 1 & 70 & 70 & 898 & 172 \\ 23 & 2 & 70 & 70 & 662 & 163\end{array}$


field

Mount Poso

Mount Poso

Mount Poso

Mount Poso

Mount Poso

Mount Poso

Mount Poso

Mount Poso

Mount Poso

Mount Poso

Mount Poso

Mount Poso

Mount Poso

Mount Poso

Mount Poso

Mount Poso

Mount Poso

Mount Poso

Mount Poso

Mount Poso

Mount Poso

Mount Poso

Mount Poso

Mount Poso

Mount Poso

Mount Poso

Mount Poso

Mount Poso

Mount Poso

Mount Poso

Mount Poso

Mount Poso

Mount Poso

Mount Poso

Mount Poso

Mount Poso

Mount Poso

Mount Poso

Mount Poso

Mount Poso

Mount Poso

Mount Poso

Mount Poso

Mount Poso

Mount Poso

Mount Poso

Mount Poso

Mount Poso

apparent

vertical
offset $\quad \begin{gathered}\text { length } \\ (\mathrm{ft})\end{gathered}$ strike note

$$
\text { offset }
$$

noter

number segment start end

$\begin{array}{cccccc}23 & 3 & 200 & 200 & 47 & 151 \\ 23 & 4 & 300 & 300 & 1419 & 148 \\ 23 & 5 & 300 & 300 & 1513 & 142 \\ 23 & 6 & 300 & 295 & 2411 & 139 \\ 23 & 7 & 405 & 430 & 4066 & 139 \\ 23 & 8 & 430 & 430 & 3073 & 139 \\ 24 & 1 & 105 & 110 & 1608 & 165 \\ 24 & 2 & 110 & 120 & 5390 & 168 \\ 24 & 3 & 120 & 120 & 1513 & 155 \\ 24 & 4 & 120 & 125 & 1844 & 147 \\ 24 & 5 & 125 & 110 & 1749 & 143 \\ 24 & 6 & 110 & 105 & 1229 & 152 \\ 24 & 7 & 105 & 90 & 1797 & 159 \\ 24 & 8 & 90 & 70 & 1371 & 160 \\ 24 & 9 & 70 & 50 & 1182 & 149 \\ 24 & 10 & 50 & 35 & 946 & 141 \\ 24 & 11 & 35 & 25 & 757 & 128 \\ 24 & 12 & 80 & 55 & 1229 & 116 \\ 24 & 13 & 55 & 25 & 1277 & 110 \\ 24 & 14 & 25 & 30 & 1844 & 115 \\ 24 & 15 & 30 & 30 & 1513 & 130 \\ 24 & 16 & 30 & 35 & 1371 & 139 \\ 24 & 17 & 35 & 35 & 1749 & 154 \\ 24 & 18 & 5 & 5 & 1466 & 163 \\ 24 & 19 & 5 & 0 & 1608 & 170 \\ 24 & 20 & 0 & 0 & 2648 & 1 \\ 25 & 1 & 0 & 45 & 1277 & 133 \\ 25 & 2 & 45 & 45 & 898 & 133 \\ 25 & 3 & 45 & 25 & 567 & 133 \\ 25 & 4 & 25 & 0 & 1560 & 133 \\ 26 & 1 & 25 & 25 & 520 & 172 \\ 26 & 2 & 25 & 20 & 1182 & 163 \\ 26 & 3 & 20 & 15 & 1088 & 156 \\ 26 & 4 & 15 & 20 & 1229 & 151 \\ 26 & 5 & 20 & 20 & 1277 & 148 \\ 26 & 6 & 20 & 0 & 2601 & 145 \\ 27 & 1 & 235 & 255 & 1513 & 128 \\ 27 & 2 & 255 & 240 & 993 & 131 \\ 28 & 1 & 155 & 140 & 3215 & 164 \\ 28 & 2 & 140 & 130 & 2884 & 167 \\ 29 & 1 & 295 & 285 & 2979 & 1 \\ 29 & 2 & 285 & 230 & 2553 & 0 \\ 29 & 3 & 290 & 170 & 2742 & 179 \\ 29 & 4 & 255 & 235 & 2411 & 177 \\ 29 & 5 & 245 & 230 & 3546 & 173 \\ 29 & 6 & 230 & 175 & 2175 & 168 \\ 30 & 1 & 45 & 45 & 378 & 120 \\ 30 & 2 & 45 & 30 & 1040 & 126\end{array}$


field

Mount Poso

Mount Poso

Mount Poso

Mount Poso

Mount Poso

Mount Poso

Mount Poso

Mount Poso

Mount Poso

Mount Poso

Mount Poso

Mount Poso

Mount Poso

Mount Poso

Mount Poso

Mount Poso

Mount Poso

Mount Poso

Mount Poso

Mount Poso

Mount Poso

Mount Poso

Mount Poso

Mount Poso

Mount Poso

Mount Poso

Mount Poso

Mount Poso

Mount Poso

Mount Poso

Mount Poso

Mount Poso

Mount Poso

Mount Poso

Mount Poso

Mount Poso

Mount Poso

Mount Poso

Mount Poso

Mount Poso

Mount Poso

Mount Poso

Mount Poso

Mount Poso

Mount Poso

Mount Poso

Mount Poso

Mount Poso

apparent

$\begin{array}{ccc}\begin{array}{c}\text { vertical } \\ \text { offset }\end{array} & \begin{array}{c}\text { length } \\ \text { (ft) }\end{array} \text { strike note }\end{array}$

number segment start end

$\begin{array}{cccccc}30 & 3 & 30 & 20 & 993 & 131 \\ 30 & 4 & 20 & 20 & 804 & 139 \\ 30 & 5 & 20 & 15 & 1040 & 148 \\ 30 & 6 & 70 & 90 & 993 & 160 \\ 31 & 1 & 55 & 55 & 615 & 141 \\ 31 & 2 & 55 & 60 & 2033 & 145 \\ 31 & 3 & 60 & 60 & 1702 & 151 \\ 31 & 4 & 60 & 75 & 1182 & 158 \\ 31 & 5 & 75 & 85 & 1040 & 168 \\ 32 & 1 & 55 & 85 & 1371 & 1 \\ 32 & 2 & 85 & 90 & 567 & 165 \\ 32 & 3 & 90 & 125 & 2411 & 158 \\ 32 & 4 & 125 & 140 & 1371 & 163 \\ 32 & 5 & 95 & 110 & 1560 & 166 \\ 32 & 6 & 110 & 125 & 1702 & 173 \\ 33 & 1 & 110 & 105 & 2175 & 14 \\ 33 & 2 & 105 & 105 & 1608 & 15 \\ 33 a & 1 & 115 & 115 & 3452 & 157 \\ 33 a & 2 & 115 & 110 & 2506 & 154 \\ 34 & 1 & 45 & 30 & 1749 & 177 \\ 34 & 2 & 30 & 15 & 1749 & 174 \\ 34 & 3 & 15 & 5 & 1419 & 172 \\ 34 & 4 & 105 & 75 & 1655 & 170 \\ 35 & 1 & 50 & 50 & 189 & 59 \\ 35 & 2 & 90 & 90 & 1419 & 59 \\ 35 & 3 & 90 & 85 & 1324 & 58 \\ 35 & 4 & 85 & 75 & 1054 & 58 \\ 35 & 5 & 65 & 60 & 236 & 58 \\ 35 & 6 & 20 & 25 & 426 & 58 \\ 36 & 1 & 30 & 0 & 1466 & 79 \\ 36 & 2 & 105 & 185 & 1891 & 79 \\ 37 & 1 & 0 & 20 & 851 & 60 \\ 37 & 2 & 20 & 25 & 1371 & 57 \\ 37 & 3 & 25 & 15 & 1324 & 60 \\ 37 & 4 & 15 & 15 & 1513 & 61 \\ 38 & 1 & 75 & 70 & 1797 & 43 \\ 38 & 2 & 70 & 50 & 804 & 42 \\ 38 & 3 & 50 & 50 & 2080 & 43 \\ 39 & 1 & & & 1040 & 119 \\ 40 & 1 & & & 757 & 117 \\ 41 & 1 & 0 & 0 & 2317 & 5 \\ 42 & 1 & 80 & 85 & 757 & 95 \\ 42 & 2 & 85 & 90 & 2080 & 99 \\ 43 & 1 & 65 & 65 & 2317 & 61 \\ 44 & 1 & 0 & 5 & 520 & 97 \\ 44 & 2 & 5 & 5 & 2317 & 97 \\ 45 & 1 & 90 & 90 & 851 & 90 \\ 45 & 2 & 90 & 85 & 1277 & 90\end{array}$


field

Mount Poso

Mount Poso

Mount Poso

Mount Poso

Mount Poso

Mount Poso

Mount Poso

Mount Poso

Mount Poso

Mount Poso

Mount Poso

Mount Poso

Mount Poso

Mount Poso

Mount Poso

Mount Poso

Mount Poso

Mount Poso

Mount Poso

Mount Poso

Mount Poso

Mount Poso

Mount Poso

Mount Poso

Mount Poso

Mount Poso

Mount Poso

Mount Poso

Mount Poso

Mount Poso

Mount Poso

Mount Poso

Mount Poso

Mount Poso

Mount Poso

Mount Poso

Mount Poso

Mount Poso

Mount Poso

Mount Poso

Mount Poso

Mount Poso

Mount Poso

Mount Poso

Mount Poso

Mount Poso

Mount Poso

Mount Poso apparent

$\begin{array}{cc}\begin{array}{c}\text { vertical length } \\ \text { offset }\end{array} & (\mathrm{ft})\end{array}$ strike note

number segment start end

$\begin{array}{llllll}45 & 3 & 85 & 100 & 1939 & 91\end{array}$

$\begin{array}{llllll}45 & 4 & 50 & 50 & 1135 & 90\end{array}$

$\begin{array}{llllll}45 & 5 & 50 & 65 & 1324 & 86\end{array}$

$\begin{array}{llllll}45 & 6 & 65 & 20 & 851 & 77\end{array}$

$\begin{array}{llllll}45 & 7 & 85 & 110 & 1135 & 68\end{array}$

$\begin{array}{llllll}46 & 1 & 15 & 40 & 1608 & 76\end{array}$

$\begin{array}{llllll}46 & 2 & 40 & 35 & 473 & 74\end{array}$

$\begin{array}{llllll}46 & 3 & 25 & 30 & 3499 & 75\end{array}$

$\begin{array}{llllll}46 & 4 & 25 & 25 & 236 & 75\end{array}$

$\begin{array}{llllll}46 & 5 & 15 & 15 & 662 & 75\end{array}$

$\begin{array}{llllll}46 & 6 & 25 & 25 & 3404 & 75\end{array}$

$\begin{array}{llllll}47 & 1 & 105 & 105 & 1466 & 82\end{array}$

$\begin{array}{llllll}47 & 2 & 175 & 195 & 1844 & 80\end{array}$

$\begin{array}{llllll}47 & 3 & 55 & 15 & 2790 & 79\end{array}$

$\begin{array}{llllll}47 & 4 & 15 & 5 & 1844 & 78\end{array}$

$\begin{array}{llllll}47 & 5 & 20 & 30 & 804 & 76\end{array}$

$\begin{array}{llllll}48 & 1 & 100 & 120 & 1371 & 55\end{array}$

$\begin{array}{llllll}48 & 2 & 65 & 60 & 1466 & 58\end{array}$

$\begin{array}{llllll}48 & 3 & 60 & 15 & 1608 & 57\end{array}$

$\begin{array}{llllll}49 & 1 & 0 & 20 & 1182 & 54\end{array}$

$\begin{array}{llllll}49 & 2 & 20 & 0 & 709 & 54\end{array}$

$\begin{array}{llllll}50 & 1 & 260 & 270 & 2317 & 23\end{array}$

$\begin{array}{llllll}51 & 1 & 100 & 100 & 6147 & 98\end{array}$

$\begin{array}{llllll}52 & 1 & 110 & 115 & 1797 & 50\end{array}$

$\begin{array}{llllll}52 & 2 & 115 & 115 & 2601 & 51\end{array}$

$\begin{array}{llllll}53 & 1 & 0 & 25 & 520 & 60\end{array}$

$\begin{array}{llllll}53 & 2 & 210 & 205 & 1182 & 64\end{array}$

$\begin{array}{llllll}54 & 1 & 110 & 120 & 1088 & 60\end{array}$

$\begin{array}{llllll}54 & 2 & 120 & 100 & 2364 & 60\end{array}$

$\begin{array}{llllll}55 & 1 & 85 & 120 & 2459 & 35\end{array}$

$\begin{array}{llllll}55 & 2 & 120 & 110 & 2790 & 34\end{array}$

$\begin{array}{llllll}56 & 1 & 55 & 55 & 1466 & 64\end{array}$

$\begin{array}{llllll}57 & 1 & 70 & 75 & 2742 & 81\end{array}$

$\begin{array}{llll}57 & 2 & 1797 & 84\end{array}$

$\begin{array}{llllll}58 & 1 & 45 & 45 & 1655 & 37\end{array}$

$\begin{array}{llllll}58 & 2 & 45 & 45 & 1844 & 44\end{array}$

$\begin{array}{llllll}58 & 3 & 45 & 45 & 1797 & 48\end{array}$

$\begin{array}{llllll}59 & 1 & 660 & 660 & 2648 & 71\end{array}$

$\begin{array}{llllll}59 & 2 & 570 & 585 & 2459 & 75\end{array}$

$\begin{array}{llllll}59 & 3 & 630 & 625 & 1655 & 78\end{array}$

$\begin{array}{llllll}59 & 4 & 625 & 620 & 1560 & 79\end{array}$

$\begin{array}{llllll}59 & 5 & 620 & 615 & 1135 & 84\end{array}$

$\begin{array}{llllll}59 & 6 & 730 & 745 & 1513 & 84\end{array}$

$\begin{array}{llllll}59 & 7 & 745 & 765 & 1891 & 88\end{array}$

$\begin{array}{llllll}59 & 8 & 465 & 780 & 2128 & 89\end{array}$

$\begin{array}{llllll}59 & 9 & 640 & 615 & 473 & 87\end{array}$

$\begin{array}{llllll}59 & 10 & 455 & 470 & 1182 & 86\end{array}$

$\begin{array}{llllll}59 & 11 & 295 & 300 & 1419 & 83\end{array}$ 
field

Mount Poso

Mount Poso

Mount Poso

Mount Poso

Mount Poso

Mount Poso

Mount Poso

Mount Poso

Mount Poso

Mount Poso

Mount Poso

Mount Poso

Mount Poso

Mount Poso

Mount Poso

Mount Poso

Mount Poso

Mount Poso

Mount Poso

Mount Poso

Mount Poso

Mount Poso

Mount Poso

Mount Poso

Poso Creek

Poso Creek

Poso Creek

Poso Creek

Poso Creek

Poso Creek

Poso Creek

Poso Creek

Poso Creek

Poso Creek

Poso Creek

Poso Creek

Poso Creek

Poso Creek

Poso Creek

Poso Creek

Poso Creek

Poso Creek

Poso Creek

Poso Creek

Poso Creek

Poso Creek

Poso Creek

Poso Creek

apparent

vertical
offset $\quad \begin{gathered}\text { length } \\ (\mathrm{ft})\end{gathered}$ strike note

number segment start end

$\begin{array}{llllll}59 & 12 & 410 & 410 & 804 & 81\end{array}$

$\begin{array}{llllll}59 & 13 & 300 & 295 & 804 & 84\end{array}$

$\begin{array}{llllll}59 & 14 & 295 & 290 & 757 & 92\end{array}$

$\begin{array}{llllll}59 & 15 & 290 & 295 & 1371 & 99\end{array}$

$\begin{array}{llllll}59 & 16 & 400 & 385 & 1371 & 106\end{array}$

$\begin{array}{llllll}59 & 17 & 385 & 365 & 1844 & 114\end{array}$

$\begin{array}{llllll}59 & 18 & 290 & 295 & 1939 & 120\end{array}$

$\begin{array}{llllll}59 & 19 & 295 & 300 & 2222 & 121\end{array}$

$\begin{array}{llllll}60 & 1 & 40 & 65 & 1182 & 153\end{array}$

$\begin{array}{llllll}60 & 2 & 175 & 160 & 2175 & 162\end{array}$

$\begin{array}{llllll}61 & 1 & 105 & 105 & 1229 & 85\end{array}$

$\begin{array}{llllll}61 & 2 & 105 & 100 & 1466 & 75\end{array}$

$\begin{array}{llllll}62 & 1 & 265 & 270 & 1324 & 51\end{array}$

$\begin{array}{llllll}62 & 2 & 270 & 275 & 1277 & 55\end{array}$

$\begin{array}{llllll}62 & 3 & 275 & 280 & 1229 & 62\end{array}$

$\begin{array}{llllll}62 & 4 & 280 & 300 & 1324 & 71\end{array}$

$\begin{array}{llllll}63 & 1 & 235 & 230 & 1135 & 44\end{array}$

$\begin{array}{llllll}63 & 2 & 230 & 220 & 1324 & 44\end{array}$

$\begin{array}{llllll}63 & 3 & 180 & 180 & 1513 & 53\end{array}$

$\begin{array}{llllll}64 & 1 & 90 & 90 & 851 & 21\end{array}$

$\begin{array}{llllll}64 & 2 & 95 & 95 & 851 & 30\end{array}$

$\begin{array}{llllll}64 & 3 & 100 & 100 & 757 & 34\end{array}$

$\begin{array}{llllll}64 & 4 & 105 & 105 & 757 & 41\end{array}$

$\begin{array}{llllll}64 & 5 & 110 & 110 & 946 & 54\end{array}$

$\begin{array}{llll}1 & 1 & 1068 & 118\end{array}$

$\begin{array}{llll}1 & 2 & 1437 & 123\end{array}$

$\begin{array}{llll}1 & 3 & 2358 & 129\end{array}$

$\begin{array}{lllll}1 & 4 & 847 & 125\end{array}$

$\begin{array}{llllll}1 & 5 & 245 & 295 & 2431 & 120\end{array}$

$\begin{array}{llllll}1 & 6 & 295 & 330 & 2247 & 123\end{array}$

$\begin{array}{llllll}1 & 7 & 140 & 160 & 1289 & 127\end{array}$

$\begin{array}{llllll}1 & 8 & 160 & 225 & 1768 & 127\end{array}$

$\begin{array}{llllll}1 & 9 & 265 & 315 & 1031 & 129\end{array}$

$\begin{array}{llll}1 & 10 & 3684 & 126\end{array}$

$\begin{array}{llll}2 & 1 & 1584 & 122\end{array}$

$\begin{array}{llll}3 & 1 & 553 & 128\end{array}$

$\begin{array}{llll}3 & 2 & 1510 & 133\end{array}$

$\begin{array}{llll}3 & 3 & 921 & 122\end{array}$

$\begin{array}{llllll}4 & 1 & 15 & 0 & 1437 & 168\end{array}$

$\begin{array}{llllll}4 & 2 & 0 & 5 & 442 & 167\end{array}$

$\begin{array}{llllll}4 & 3 & 5 & 25 & 1289 & 164\end{array}$

$\begin{array}{llll}4 & 4 & 1068 & 167\end{array}$

$\begin{array}{llllll}4 & 5 & 20 & 15 & 5489 & 160\end{array}$

$\begin{array}{llllll}4 & 6 & 15 & 15 & 626 & 169\end{array}$

$\begin{array}{llllll}4 & 7 & 15 & 10 & 553 & 173\end{array}$

$\begin{array}{llllll}4 & 8 & 10 & 5 & 663 & 178\end{array}$

$\begin{array}{llllll}4 & 9 & 5 & 0 & 921 & 5\end{array}$

$\begin{array}{llllll}5 & 1 & 10 & 20 & 1105 & 157\end{array}$ 
field

$\begin{array}{ccc}\begin{array}{c}\text { vertical } \\ \text { offset }\end{array} & \begin{array}{c}\text { length } \\ \text { (ft) }\end{array} \text { strike note }\end{array}$

Proek

Poso Creek

Poso Creek

Poso Creek

Poso Creek

Poso Creek

Poso Creek

Poso Creek

Poso Creek

Poso Creek

Poso Creek

Poso Creek

Poso Creek

Poso Creek

Poso Creek

Poso Creek

Poso Creek

Poso Creek

Poso Creek

Poso Creek

Poso Creek

Poso Creek

Poso Creek

Poso Creek

Poso Creek

Poso Creek

Poso Creek

Poso Creek

Poso Creek

Poso Creek

Poso Creek

Poso Creek

Poso Creek

Poso Creek

Poso Creek

Poso Creek

Poso Creek

Poso Creek

Poso Creek

Poso Creek

Poso Creek

Poso Creek

Poso Creek

Poso Creek

Poso Creek

Poso Creek

Poso Creek

Poso Creek

number segment start end

$\begin{array}{cccccc}5 & 2 & 20 & 0 & 1695 & 155 \\ 5 & 3 & 20 & 50 & 1879 & 152 \\ 5 & 4 & 50 & 60 & 1510 & 147 \\ 5 & 5 & 60 & 70 & 1510 & 140 \\ 6 & 1 & 260 & 230 & 1695 & 177 \\ 6 & 2 & 230 & 190 & 2173 & 1 \\ 6 & 3 & 190 & 165 & 1584 & 5 \\ 6 & 4 & 165 & 120 & 1805 & 4 \\ 6 & 5 & 120 & 85 & 1252 & 178 \\ 6 & 6 & 85 & 25 & 1695 & 174 \\ 6 & 7 & 25 & 65 & 921 & 169 \\ 6 & 8 & 65 & 50 & 1363 & 166 \\ 6 & 9 & 50 & 35 & 1031 & 157 \\ 6 & 10 & 35 & 20 & 1326 & 149 \\ 6 & 11 & 20 & 15 & 553 & 160 \\ 6 & 12 & 15 & 20 & 295 & 169 \\ 6 & 13 & 20 & 30 & 1252 & 7 \\ 6 & 14 & 30 & 0 & 1068 & 6 \\ 6 & 15 & 0 & 15 & 1437 & 3 \\ 6 & 16 & 15 & 50 & 810 & 0 \\ 6 & 17 & 50 & 85 & 995 & 175 \\ 6 & 18 & 85 & 90 & 810 & 169 \\ 6 & 19 & 90 & 105 & 1547 & 163 \\ 6 & 20 & 105 & 120 & 1658 & 155 \\ 7 & 1 & 40 & 30 & 1473 & 175 \\ 7 & 2 & 30 & 15 & 1216 & 178 \\ 7 & 3 & 15 & 5 & 516 & 0 \\ 7 & 4 & 5 & 95 & 2284 & 0 \\ 7 & 5 & 95 & 130 & 4568 & 179 \\ 7 & 6 & 130 & 120 & 2836 & 175 \\ 7 & 7 & 120 & 115 & 2100 & 178 \\ 7 & 8 & 115 & 65 & 2284 & 0 \\ 7 & 9 & 65 & 70 & 958 & 0 \\ 7 & 10 & 70 & 40 & 1879 & 2 \\ 7 & 11 & 40 & 30 & 1289 & 2 \\ 7 & 12 & 30 & 20 & 1142 & 0 \\ 7 & 13 & 140 & 140 & 2726 & 0 \\ 7 & 14 & 140 & 140 & 2947 & 178 \\ 7 & 15 & & & 884 & 178 \\ 8 & 1 & & & 2394 & 175 \\ 8 & 2 & & & 2652 & 177 \\ 8 & 3 & & & 2100 & 178 \\ 8 & 4 & 20 & 15 & 1805 & 179 \\ 8 & 5 & 15 & 0 & 2984 & 1 \\ 9 & 1 & & & 1473 & 160 \\ 9 & 2 & & & 2468 & 165 \\ 9 & 3 & & & 1216 & 166 \\ 9 & 4 & & & 1252 & 169\end{array}$


field

Poso Creek

Poso Creek

Poso Creek

Poso Creek

Poso Creek

Poso Creek

Poso Creek

Poso Creek:McVan

Poso Creek:McVan

Poso Creek:McVan

Poso Creek:McVan

Poso Creek:McVan

Poso Creek:McVan

Poso Creek:McVan

Poso Creek:McVan

Poso Creek:McVan

Poso Creek:McVan

Poso Creek:McVan

Poso Creek:McVan

Poso Creek:McVan

Poso Creek:McVan

Poso Creek:McVan

Poso Creek:McVan

Poso Creek:McVan

Poso Creek:McVan

Poso Creek:McVan

Poso Creek:McVan

Poso Creek:McVan

Poso Creek:McVan

Poso Creek:McVan

Poso Creek:McVan

Poso Creek:McVan

Poso Creek:McVan

Poso Creek:McVan

Poso Creek:McVan

Poso Creek:McVan

Poso Creek:McVan

Rio Bravo

Rio Bravo

Rio Bravo

Rio Bravo

Rio Bravo

Rio Bravo

Rio Bravo

Rio Bravo

Rio Bravo

Rio Bravo

Rio Bravo apparent

$\begin{array}{cc}\text { vertical length } \\ \text { offset } & (\mathrm{ft})\end{array}$ strike note

number segment start end

\begin{tabular}{|c|c|c|c|c|c|}
\hline 9 & 5 & & & 1547 & 172 \\
\hline 9 & 6 & & & 1621 & 175 \\
\hline 10 & 1 & 0 & 10 & 553 & 85 \\
\hline 10 & 2 & 10 & 10 & 995 & 85 \\
\hline 11 & 1 & 0 & 10 & 332 & 112 \\
\hline 11 & 2 & 10 & 10 & 368 & 112 \\
\hline 11 & 3 & 10 & 0 & 553 & 112 \\
\hline 1 & 1 & & & 631 & 118 \\
\hline 1 & 2 & & & 501 & 125 \\
\hline 1 & 3 & & & 305 & 132 \\
\hline 2 & 1 & & & 2885 & 146 \\
\hline 3 & 1 & & & 4268 & 33 \\
\hline 4 & 1 & & & 446 & 123 \\
\hline 5 & 1 & & & 4072 & 31 \\
\hline 6 & 1 & & & 631 & 122 \\
\hline 6 & 2 & & & 664 & 131 \\
\hline 6 & 3 & & & 1165 & 141 \\
\hline 6 & 4 & & & 457 & 147 \\
\hline 6 & 5 & & & 697 & 154 \\
\hline 6 & 6 & & & 871 & 161 \\
\hline 6 & 7 & & & 849 & 163 \\
\hline 6 & 8 & & & 1100 & 166 \\
\hline 6 & 9 & & & 1285 & 168 \\
\hline 7 & 1 & 70 & 65 & 980 & 148 \\
\hline 7 & 2 & 65 & 60 & 588 & 153 \\
\hline 7 & 3 & 60 & 55 & 490 & 162 \\
\hline 7 & 4 & 55 & 50 & 1176 & 174 \\
\hline 7 & 5 & 50 & 100 & 762 & 175 \\
\hline 7 & 6 & 100 & 85 & 1132 & 177 \\
\hline 7 & 7 & & & 980 & 178 \\
\hline 8 & 1 & & & 523 & 130 \\
\hline 8 & 2 & & & 631 & 139 \\
\hline 8 & 3 & & & 403 & 145 \\
\hline 8 & 4 & & & 1012 & 148 \\
\hline 8 & 5 & & & 708 & 155 \\
\hline 9 & 1 & & & 599 & 165 \\
\hline 9 & 2 & & & 1644 & 169 \\
\hline 1 & 1 & & & 386 & 6 \\
\hline 1 & 2 & 10 & 5 & 134 & 6 \\
\hline 1 & 3 & 5 & 0 & 252 & 6 \\
\hline 1 & 4 & 0 & 0 & 185 & 6 \\
\hline 1 & 5 & 0 & 5 & 168 & 6 \\
\hline 1 & 6 & 5 & 0 & 117 & 6 \\
\hline 1 & 7 & 0 & 5 & 117 & 6 \\
\hline 1 & 8 & 5 & 25 & 654 & 6 \\
\hline 1 & 9 & 25 & 10 & 302 & 4 \\
\hline 1 & 10 & 10 & 5 & 839 & 4 \\
\hline 1 & 11 & 5 & 5 & . & $r^{\prime}$ \\
\hline
\end{tabular}


field

Rio Bravo

Rio Bravo

Rio Bravo

Rio Bravo

Rio Bravo

Rio Bravo

Rio Bravo

Rio Bravo

Rio Bravo

Rio Bravo

Rio Bravo

Rio Bravo

Rio Bravo

Rio Bravo

Rio Bravo

Rio Bravo

Rio Bravo

Rio Bravo

Rio Bravo

Rio Bravo

Rio Bravo

Rosedale

Rosedale

Rosedale

Rosedale

Rosedale

Rosedale

Rosedale

Rosedale

Rosedale

Rosedale

Rosedale

Rosedale

Rosedale

Rosedale

Rosedale

Rosedale

Rosedale

Rosedale

Rosedale

Rosedale

Rosedale

Rosedale

Rosedale

Rosedale

Rosedale

Rosedale

Rosedale apparent

fault

vertical

offset

length

(ft)

strike

note

number segment start end

1
2
2
2
2
2
2
2
2
2
2

$\begin{array}{llll}5 & 0 & 755 & 2\end{array}$

$587 \quad 3$
70

$\begin{array}{llll}70 & 115 & 252 & 3\end{array}$

$\begin{array}{llll}115 & 135 & 235 & 3\end{array}$

$\begin{array}{llll}135 & 135 & 218 & 3\end{array}$

$\begin{array}{llll}135 & 145 & 235 & 3\end{array}$

$\begin{array}{llll}145 & 135 & 268 & 3\end{array}$

$\begin{array}{llll}135 & 150 & 336 & 3\end{array}$

$\begin{array}{llll}150 & 150 & 319 & 3\end{array}$

$\begin{array}{llll}150 & 140 & 436 & 3\end{array}$

$\begin{array}{llll}140 & 90 & 520 & 3\end{array}$

$\begin{array}{llll}90 & 70 & 872 & 3\end{array}$

$\begin{array}{llll}70 & 40 & 621 & 0\end{array}$

$\begin{array}{llll}40 & 25 & 302 & 0\end{array}$

$\begin{array}{llll}25 & 20 & 721 & 0\end{array}$

$\begin{array}{llll}20 & 15 & 755 & 0\end{array}$

$\begin{array}{llll}15 & 0 & 788 & 0\end{array}$

$1527 \quad 146$

$1241 \quad 148$

$1409 \quad 151$

$1963 \quad 152$

12012

$\begin{array}{llll}90 & 60 & 1327 & 3\end{array}$

$\begin{array}{llll}60 & 40 & 1255 & 2\end{array}$

$\begin{array}{llll}40 & 50 & 1381 & 3\end{array}$

$1829 \quad 2$

$2349 \quad 166$ Rosedale Fault

$717 \quad 169$ Rosedale Fault

$251 \quad 172$ Rosedale Fault

$\begin{array}{lllll}70 & 100 & 1685 & 178 & \text { Rosedale Fault }\end{array}$

$\begin{array}{lllll}100 & 60 & 1112 & 178 & \text { Rosedale Fault }\end{array}$

$\begin{array}{lllll}60 & 100 & 1506 & 179 & \text { Rosedale Fault }\end{array}$

$\begin{array}{lllll}100 & 85 & 484 & 2 & \text { Rosedale Fault }\end{array}$

$\begin{array}{lllll}85 & 70 & 520 & 9 & \text { Rosedale Fault }\end{array}$

$\begin{array}{lllll}215 & 140 & 520 & 7 & \text { Rosedale Fault }\end{array}$

$\begin{array}{lllll}140 & 90 & 377 & 2 & \text { Rosedale Fault }\end{array}$

$\begin{array}{lllll}90 & 30 & 412 & 175 & \text { Rosedale Fault }\end{array}$

$914 \quad 176$ Rosedale Fault

753179 Rosedale Fault

$484 \quad 2$ Bellevue Fault

6637 Bellevue Fault

$2994 \quad 13$ Bellevue Fault

$502 \quad 21$ Bellevue Fault

55630 Bellevue Fault

26928 Bellevue Fault

52023 Bellevue Fault

16672 Bellevue Fault

466178 Bellevue Fault 
field

Rosedale

Rosedale

Rosedale

Rosedale

Rosedale

Rosedale

Rosedale

Rosedale

Rosedale Ranch

Rosedale Ranch

Rosedale Ranch

Rosedale Ranch

Rosedale Ranch

Rosedale Ranch

Rosedale Ranch

Rosedale Ranch

Rosedale Ranch

Rosedale Ranch

Rosedale Ranch

Rosedale Ranch

Rosedale Ranch

Rosedale Ranch

Rosedale Ranch

Rosedale Ranch

Rosedale Ranch

Rosedale Ranch

Rosedale Ranch

Rosedale Ranch

Rosedale Ranch

Rosedale Ranch

Rosedale Ranch

Rosedale Ranch

Rosedale Ranch

Rosedale Ranch

Rosedale Ranch

Rosedale Ranch

Rosedale Ranch

Rosedale Ranch

Rosedale Ranch

Rosedale Ranch

Rosedale Ranch

Rosedale Ranch

Rosedale Ranch

Rosedale Ranch

Rosedale Ranch

Rosedale Ranch

Rosedale Ranch

Rosedale Ranch apparent

vertical
offset $\quad \begin{gathered}\text { length } \\ (\mathrm{ft})\end{gathered}$ strike note

number segment start end

$3 \quad 10$

$3 \quad 11$

$3 \quad 12$

$4 \quad 1$

42

43

$4 \quad 4$

$5 \quad 1$

$1 \quad 1$

12

13

14

21

22

23

1

12

$1 \quad 40 \quad 35$

$35 \quad 25$

$25 \quad 10$

$645 \quad 171$ Bellevue Fault

645165 Bellevue Fault

4321170 Bellevue Fault

$\begin{array}{llll}10 & 0 & 412 & 47\end{array}$

$\begin{array}{llll}140 & 95 & 2080 & 141\end{array}$

$\begin{array}{llll}30 & 35 & 396 & 158\end{array}$

$\begin{array}{llll}35 & 45 & 960 & 160\end{array}$

$\begin{array}{llll}45 & 55 & 1200 & 164\end{array}$

$\begin{array}{llll}55 & 50 & 2424 & 167\end{array}$

$\begin{array}{llll}30 & 30 & 768 & 1\end{array}$

$\begin{array}{llll}30 & 30 & 1044 & 5\end{array}$

$\begin{array}{llll}30 & 30 & 1116 & 9\end{array}$

$\begin{array}{llll}30 & 30 & 336 & 9\end{array}$

$\begin{array}{llll}25 & 25 & 636 & 14\end{array}$

$\begin{array}{llll}25 & 25 & 444 & 18\end{array}$

$\begin{array}{llll}25 & 5 & 2256 & 19\end{array}$

$\begin{array}{llll}5 & 0 & 828 & 20\end{array}$

$2988 \quad 164$

$540 \quad 165$

$444 \quad 170$

$444 \quad 174$

10321

9604

$1260 \quad 5$

$864 \quad 163$

$720 \quad 159$

$636 \quad 157$

$528 \quad 159$

$624 \quad 165$

$720 \quad 176$

$660 \quad 174$

$720 \quad 177$

$768 \quad 0$

$744 \quad 2$

10924

$\begin{array}{llll}40 & 25 & 2280 & 167\end{array}$

$\begin{array}{llll}25 & 15 & 648 & 166\end{array}$

$\begin{array}{llll}15 & 5 & 420 & 169\end{array}$

$\begin{array}{llll}5 & 10 & 696 & 176\end{array}$

$\begin{array}{llll}10 & 10 & 708 & 1\end{array}$

$\begin{array}{llll}10 & 10 & 720 & 5\end{array}$

$\begin{array}{llll}10 & 10 & 984 & 7\end{array}$

$\begin{array}{llll}10 & 10 & 732 & 9\end{array}$

$\begin{array}{llll}10 & 10 & 924 & 14\end{array}$

$\begin{array}{llll}6 & 1 & 684 & 179\end{array}$ 
field

Rosedale Ranch

Rosedale Ranch

Rosedale Ranch

Rosedale Ranch

Rosedale Ranch

Rosedale Ranch

Rosedale Ranch

Rosedale Ranch

Rosedale Ranch

Rosedale Ranch

Rosedale Ranch

Rosedale Ranch

Seventh Standard

Seventh Standard

Seventh Standard

Seventh Standard

Seventh Standard

Shafter

Shafter

Shafter

Shafter

Shafter

Shafter

Shafter

Shafter

Shafter Southeast Gas

Shafter Southeast Gas

Shafter Southeast Gas

Shafter Southeast Gas

Shafter Southeast Gas

Shafter Southeast Gas

Strand

Strand

Strand

Strand

Strand

Strand

Strand

Strand

Strand

Strand

Strand

Strand

Strand

Strand

Strand

Strand

Strand apparent

$\begin{array}{cc}\begin{array}{c}\text { vertical length } \\ \text { offset }\end{array} & (\mathrm{ft})\end{array}$ strike note

number segment start end

\begin{tabular}{|c|c|c|c|c|c|}
\hline 6 & 2 & & & 852 & 2 \\
\hline 6 & 3 & & & 708 & 1 \\
\hline 6 & 4 & & & 588 & 179 \\
\hline 6 & 5 & & & 684 & 177 \\
\hline 6 & 6 & & & 708 & 171 \\
\hline 6 & 7 & & & 720 & 167 \\
\hline 6 & 8 & & & 612 & 163 \\
\hline 6 & 9 & & & 660 & 158 \\
\hline 7 & 1 & 0 & 20 & 1008 & 39 \\
\hline 7 & 2 & 30 & 10 & 720 & 41 \\
\hline 7 & 3 & 10 & 0 & 204 & 41 \\
\hline 7 & 4 & 0 & 5 & 216 & 41 \\
\hline 1 & 1 & 330 & 330 & 614 & 169 \\
\hline 1 & 2 & 330 & 330 & 444 & 175 \\
\hline 1 & 3 & 330 & 335 & 2476 & 0 \\
\hline 1 & 4 & 335 & 335 & 936 & 2 \\
\hline 1 & 5 & 335 & 335 & 1909 & 0 \\
\hline 1 & 1 & 20 & 20 & 1178 & 143 \\
\hline 1 & 2 & 20 & 0 & 1217 & 146 \\
\hline 1 & 3 & 0 & 30 & 2552 & 147 \\
\hline 1 & 4 & 30 & 60 & 2100 & 152 \\
\hline 1 & 5 & 60 & 90 & 2100 & 156 \\
\hline 1 & 6 & 90 & 90 & 2983 & 160 \\
\hline 1 & 7 & 90 & 90 & 2316 & 163 \\
\hline 1 & 8 & 90 & 90 & 2611 & 165 \\
\hline 1 & 1 & & & 6046 & 148 \\
\hline 1 & 2 & 11 & 3 & 3015 & 148 \\
\hline 1 & 3 & 20 & 20 & 3553 & 147 \\
\hline 1 & 4 & & & 2119 & 147 \\
\hline 2 & 1 & 20 & 20 & 5476 & 17 \\
\hline 2 & 2 & 20 & 17 & 2004 & 16 \\
\hline 1 & 1 & & & 3710 & 55 \\
\hline 1 & 2 & & & 3869 & 54 \\
\hline 1 & 3 & & & 4825 & 52 \\
\hline 1 & 4 & & & 1775 & 51 \\
\hline 2 & 1 & 0 & 10 & 1206 & 62 \\
\hline 2 & 2 & 10 & 10 & 1525 & 62 \\
\hline 2 & 3 & 10 & 0 & 956 & 60 \\
\hline 2 & 4 & 0 & 5 & 341 & 59 \\
\hline 2 & 5 & 5 & 0 & 137 & 59 \\
\hline 2 & 6 & 0 & 20 & 569 & 59 \\
\hline 2 & 7 & 20 & 25 & 1320 & 59 \\
\hline 2 & 8 & 25 & 25 & 523 & 59 \\
\hline 3 & 1 & 90 & 60 & 2390 & 169 \\
\hline 3 & 2 & 15 & 20 & 2390 & 169 \\
\hline 3 & 3 & 20 & 0 & 660 & 169 \\
\hline 3 & 4 & 0 & 5 & 273 & 169 \\
\hline 3 & 5 & 40 & 60 & 432 & 165 \\
\hline
\end{tabular}


field

$$
\text { apparent }
$$

$\begin{array}{cc}\begin{array}{c}\text { vertical length } \\ \text { offset }\end{array} & \text { (ft) }\end{array}$ strike note

Strand

Strand

Strand

Strand

Strand

Strand

Strand

Strand

Strand

Strand

Strand

Strand

Strand

Strand

Strand

Strand

Strand

Strand

Strand

Strand

Strand

Strand

Strand

Strand

Strand

Strand

Strand

Strand

Strand

Strand

Strand

Strand

Strand

Strand

Strand

Strand

Strand

Strand

Strand

Strand

Strand

Strand

Strand

Strand

number segment start end

$\begin{array}{cccccc}3 & 6 & 60 & 35 & 387 & 165 \\ 3 & 7 & 35 & 20 & 387 & 165 \\ 3 & 8 & 20 & 0 & 660 & 165 \\ 3 & 9 & 0 & 5 & 614 & 165 \\ 3 & 10 & 5 & 10 & 1593 & 165 \\ 3 & 11 & 10 & 15 & 910 & 165 \\ 3 & 12 & 15 & 20 & 2208 & 165 \\ 3 & 13 & 20 & 20 & 1616 & 165 \\ 4 & 1 & 50 & 70 & 728 & 58 \\ 4 & 2 & 70 & 50 & 637 & 58 \\ 4 & 3 & 50 & 10 & 1024 & 58 \\ 5 & 1 & & & 6236 & 152 \\ 5 & 2 & 5 & 30 & 1206 & 152 \\ 5 & 3 & 30 & 10 & 3209 & 152 \\ 5 & 4 & 10 & 15 & 1730 & 153 \\ 5 & 5 & 15 & 5 & 2185 & 153 \\ 6 & 1 & 45 & 20 & 933 & 69 \\ 6 & 2 & 20 & 15 & 592 & 69 \\ 6 & 3 & 15 & 25 & 387 & 69 \\ 6 & 4 & 25 & 40 & 1138 & 69 \\ 7 & 1 & & & 1001 & 73 \\ 7 & 2 & & & 1388 & 68 \\ 7 & 3 & & & 1457 & 63 \\ 7 & 4 & & & 910 & 59 \\ 7 & 5 & 10 & 0 & 205 & 59 \\ 7 & 6 & 0 & 10 & 205 & 59 \\ 7 & 7 & 10 & 5 & 546 & 57 \\ 7 & 8 & 5 & 5 & 614 & 55 \\ 7 & 9 & & & 1001 & 54 \\ 7 & 10 & & & 933 & 50 \\ 8 & 1 & 10 & 15 & 523 & 125 \\ 8 & 2 & 15 & 55 & 660 & 125 \\ 8 & 3 & 55 & 100 & 546 & 125 \\ 8 & 4 & 100 & 125 & 592 & 125 \\ 8 & 5 & 125 & 145 & 523 & 125 \\ 9 & 1 & 0 & 0 & 1161 & 78 \\ 9 & 2 & 0 & & 774 & 84 \\ 9 & 3 & & & 1297 & 76 \\ 9 & 4 & & & 1525 & 71 \\ 9 & 5 & & 10 & 1752 & 65 \\ 9 & 6 & 10 & 10 & 1183 & 63 \\ 9 & 7 & 10 & 10 & 432 & 60 \\ 9 & 8 & 10 & 35 & 910 & 59 \\ 9 & 9 & 35 & 105 & 1115 & 59\end{array}$




\section{DISCLAIMER}

This document was prepared as an account of work sponsored by the United States Government. While this document is believed to contain correct information, neither the United States Government nor any agency thereof, nor The Regents of the University of California, nor any of their employees, makes any warranty, express or implied, or assumes any legal responsibility for the accuracy, completeness, or usefulness of any information, apparatus, product, or process disclosed, or represents that its use would not infringe privately owned rights. Reference herein to any specific commercial product, process, or service by its trade name, trademark, manufacturer, or otherwise, does not necessarily constitute or imply its endorsement, recommendation, or favoring by the United States Government or any agency thereof, or The Regents of the University of California. The views and opinions of authors expressed herein do not necessarily state or reflect those of the United States Government or any agency thereof or The Regents of the University of California.

Ernest Orlando Lawrence Berkeley National Laboratory is an equal opportunity employer. 